\title{
Toward the mechanism of eIF4F-mediated ribosomal attachment to mammalian capped mRNAs
}

\author{
Parimal Kumar, Christopher U.T. Hellen, and Tatyana V. Pestova \\ Department of Cell Biology, State University of New York Downstate Medical Center, Brooklyn, New York 11203, USA
}

\begin{abstract}
Ribosomal attachment to mammalian capped mRNAs is achieved through the cap-eukaryotic initiation factor 4E (eIF4E)-eIF4G-eIF3-40S chain of interactions, but the mechanism by which mRNA enters the mRNA-binding channel of the 40S subunit remains unknown. To investigate this process, we recapitulated initiation on capped mRNAs in vitro using a reconstituted translation system. Formation of initiation complexes at 5 '-terminal AUGs was stimulated by the eIF4E-cap interaction and followed "the first AUG" rule, indicating that it did not occur by backward scanning. Initiation complexes formed even at the very $5^{\prime}$ end of mRNA, implying that Met-tRNA ${ }_{i}{ }^{\text {Met }}$ inspects mRNA from the first nucleotide and that initiation does not have a "blind spot." In assembled initiation complexes, the cap was no longer associated with eIF4E. Omission of eIF4A or disruption of eIF4E-eIF4G-eIF3 interactions converted eIF4E into a specific inhibitor of initiation on capped mRNAs. Taken together, these results are consistent with the model in which eIF4E-eIF4G-eIF3-40S interactions place eIF4E at the leading edge of the 40S subunit, and mRNA is threaded into the mRNA-binding channel such that Met-tRNA ${ }_{i}{ }^{\text {Met }}$ can inspect it from the first nucleotide. Before entering, eIF4E likely dissociates from the cap to overcome steric hindrance. We also found that the $\mathbf{m}^{7} \mathbf{G}$ cap specifically interacts with eIF31.
\end{abstract}

[Keywords: eukaryotic translation initiation; eIF4E; eIF4F; $\mathrm{m}^{7} \mathrm{G}_{\text {; }}$ eIF31; 40S ribosomal subunit]

Supplemental material is available for this article.

Received April 7, 2016; revised version accepted June 1, 2016.

Translation initiation on the majority of mammalian cellular mRNAs occurs by the scanning mechanism (Jackson et al. 2010). First, eukaryotic initiation factor 2 (eIF2), GTP, and Met-tRNA ${ }_{i}{ }^{\text {Met }}$ form a ternary complex (eIF2$\mathrm{TC})$, which, with the multisubunit eIF3 and monomeric eIF1 and eIF1A, binds to the 40S ribosomal subunit, yielding a $43 \mathrm{~S}$ preinitiation complex. Attachment of the 43S complex to capped mRNA is mediated by eIF4A, eIF4B, and eIF4F. eIF4F comprises the cap-binding protein eIF4E, the DEAD-box RNA helicase eIF4A (which also exists in a free form), and the eIF4G scaffold, which interacts with the other two subunits as well as eIF3. eIF4A's helicase activity is stimulated by both eIF4G and eIF4B. Group 4 eIFs cooperatively unwind the cap-proximal region of mRNA, preparing it for attachment of $43 \mathrm{~S}$ complexes, which is promoted by the eIF4G-eIF3 interaction. After attachment, $43 \mathrm{~S}$ complexes scan to the first AUG codon in a favorable nucleotide context, where they form $48 \mathrm{~S}$ initiation complexes with established codonanti-codon base-pairing. Group 4 eIFs also assist $43 \mathrm{~S}$ complexes during scanning. Scanning on mRNAs with highly structured 5' untranslated regions (UTRs) additionally re-

Corresponding author: tatyana.pestova@downstate.edu Article is online at http://www.genesdev.org/cgi/doi/10.1101/gad.282418. 116. quires DHX29, a DExH-box protein that interacts directly with 40 S subunits. eIF1, in cooperation with eIF1A, ensures the fidelity of initiation codon selection, discriminating against initiation at non-AUG codons and AUGs that are too close to the $5^{\prime}$ end of mRNA or have poor nucleotide context. Finally, eIF5 and eIF5B mediate joining of $48 \mathrm{~S}$ complexes with $60 \mathrm{~S}$ ribosomal subunits to form elongation-competent $80 \mathrm{~S}$ ribosomes.

Thus, attachment of $43 \mathrm{~S}$ complexes to eukaryotic capped mRNAs is achieved through the cap-eIF4EeIF4G-eIF3-40S chain of interactions. The minimal cap (cap0) consists of N7-methylguanosine linked to the first nucleotide by a $5^{\prime}-5^{\prime}$ triphosphate (ppp) bridge. In higher eukaryotes, cap0 is modified by the $2^{\prime}-\mathrm{O}$ methylation of the next two riboses, yielding "cap1" and "cap2," respectively. In the eIF4E/cap complex, the guanine base is stacked between two tryptophans on the concave surface of the factor (for review, see von der Haar et al. 2004). N7 methylation results in delocalization of the positive charge on the base in its cationic form, which enhances

(C) 2016 Kumar et al. This article is distributed exclusively by Cold Spring Harbor Laboratory Press for the first six months after the full-issue publication date (see http://genesdev.cshlp.org/site/misc/terms.xhtml). After six months, it is available under a Creative Commons License (Attribution-NonCommercial 4.0 International), as described at http:// creativecommons.org/licenses/by-nc/4.0/. 
the interactions with the $\pi$ electrons of the stacked aromatic rings (Quiocho et al. 2000), accounting for the increase of two to three orders in the affinity of binding to the N7-methylated cap over its unmethylated counterpart (Niedzwiecka et al. 2002). The interaction of eIF4E with the guanine base is further stabilized by its contacts with the ppp bridge. An additional contact involves interaction of the nucleotide adjacent to the cap with the flexible C-terminal loop of eIF4E, which results in stabilization of the latter (Tomoo et al. 2002). 2'-O methylation of the ribose is not required for the eIF4E-cap interaction but protects cellular capped mRNAs from sequestration by IFIT1 (interferon-induced protein with tetratricopeptide repeats), which interacts specifically with "cap0" mRNAs (e.g., see Kumar et al. 2014).

In ribosomal complexes, mRNA resides in the narrow channel between the head and the body of the 40S subunit. In addition to the 40S subunit itself, the channel is further constricted by eIF1, eIF1A, Met-tRNA ${ }_{i}{ }^{\text {Met }}$, and eIF2's a subunit, which interacts with the -2 and -3 positions in the mRNA (Pisarev et al. 2006; Hashem et al. 2013; Hussain et al. 2014; Llácer et al. 2015). The mechanism by which eIF4E-bound capped mRNA enters the mRNA-binding channel of the 40S subunit during initial attachment of $43 \mathrm{~S}$ complexes remains totally unknown. Because of steric hindrance, it is difficult to imagine that cap-bound eIF4E can be threaded through the channel. Therefore, depending on the position of eIF4E in ribosomal complexes and the dynamics of the eIF4E/cap interaction during the initiation process, two principal scenarios can be envisioned (Fig. 1). If eIF4E resides at the trailing edge of the $43 \mathrm{~S}$ complex (at the E-site side of the 40 S subunit) (Fig. 1A), 40S subunits would attach to a 5 -proximal but nevertheless internal region of mRNA (due to steric hindrance caused by eIF4E), which would "slot" directly into the mRNA-binding channel. In this case, initiator tRNA would not be able to inspect several
5 'terminal nucleotides whose number would depend on the distance between eIF4E and the ribosomal P site. If eIF4E's position is fixed, the eIF4E/cap interaction must eventually be broken to accommodate mRNA in the E-site side of the mRNA-binding channel, whereas if it is flexible, eIF4E might be able to move to allow mRNA to accommodate in the channel without disruption of the eIF4E/cap interaction. If eIF4E is located closer to the solvent side of the $40 \mathrm{~S}$ subunit, a substantially longer 5 '-terminal region of mRNA would be "invisible" to initiator tRNA, but accommodation of mRNA in the channel would be possible without disruption of the eIF4E/cap interaction. If eIF4E is located at the leading edge of the 43S complex (at the A-site side of the $40 \mathrm{~S}$ subunit) (Fig. 1B), mRNA would have to be "threaded" into the mRNAbinding channel, which would likely require prior disruption of the eIF4E-cap interaction to overcome steric hindrance. However, in this case, initiator tRNA would be able to inspect mRNA from the first nucleotide.

In the cap-eIF4E-eIF4G-eIF3-40S chain of interactions, eIF4G forms the main connecting link between mRNA and the $43 \mathrm{~S}$ complex. Thus, during ribosomal attachment, eIF4G coordinates the cap-binding activity of eIF4E and the RNA helicase activity of eIF4A and couples them with 43S complexes through direct interaction with eIF3. The essential central domain of eIF4G contains binding sites for eIF4A (Imataka and Sonenberg 1997) and eIF3 (LeFebvre et al. 2006; Villa et al. 2013), whereas the binding site for eIF4E is located in the $\mathrm{N}$-terminal region (Mader et al. 1995). The C-terminal domain of eIF4G, which contains the second binding site for eIF4A (Imataka and Sonenberg 1997), is not essential for eIF4G's function (Morino et al. 2000). Mammalian eIF3 comprises 13 subunits, eight ( $\mathrm{a}, \mathrm{c}, \mathrm{e}, \mathrm{f}, \mathrm{h} \mathrm{l}, \mathrm{k}$, and $\mathrm{m}$ ) of which contain PCI (proteasome, COP9/signalosome, and eIF3) or MPN (Mpr1-Pad1-N-terminal) domains. These subunits constitute eIF3's core, to which five peripheral subunits

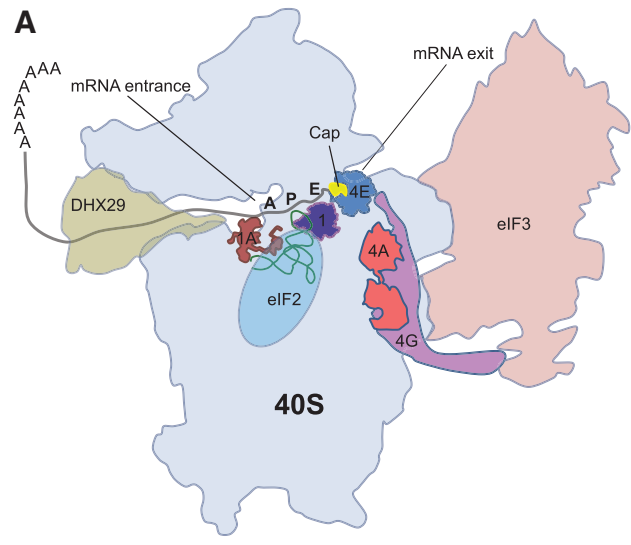

Intersubunit interface side

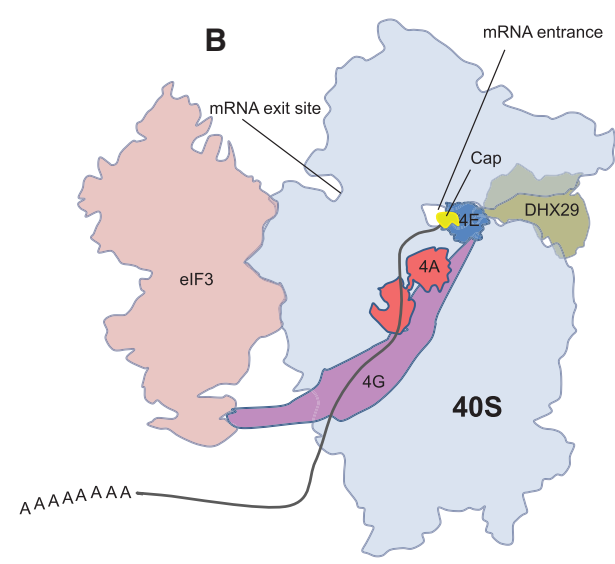

Solvent side

Figure 1. Hypothetical models of eIF4F-mediated ribosomal attachment to capped mRNAs. $(A)$ eIF4E is located at the E-site side of the $40 S$ subunit, and $40 \mathrm{~S}$ subunits attach to a 5'-proximal but internal region of mRNA, which "slots" directly into the mRNA-binding channel. Met-tRNA ${ }_{i}{ }^{\text {Met }}$ does not inspect several $5^{\prime}$-terminal nucleotides. (B) eIF4E is located at the A-site side of the 40S subunit, and mRNA is "threaded" into the mRNA-binding channel, which allows Met-tRNA ${ }_{i}{ }^{\text {Met }}$ to inspect mRNA from the first nucleotide. 
(b, d, g, i, and j) are flexibly linked. The cryo-electron microscopy (cryo-EM) structure of eIF3 in the context of the $43 \mathrm{~S}$ complex revealed that the PCI/MPN core binds at the solvent side of the $40 \mathrm{~S}$ subunit opposite the platform, and the eIF3b-eIF3i-eIF3g module resides at the mRNA entrance, whereas eIF3d is located near the mRNA exit (des Georges et al. 2015). eIF4G interacts with eIF3e via one region (LeFebvre et al. 2006) and with the eIF3c and eIF3d subunits through an adjacent site (Villa et al. 2013). Although the cryo-EM structure allowed the ribosomal position of eIF4G-binding subunits of eIF3 to be located, the ribosomal orientation of eIF4F and the position of eIF4E could not be proposed with even a reasonable degree of certainty.

Therefore, to investigate the mechanism of eIF4F-mediated attachment of $43 \mathrm{~S}$ preinitiation complexes to capped mRNAs, we used a functional approach based on recapitulation of this process in vitro using a reconstituted mammalian translation system.

\section{Results}

To investigate the mechanism of eIF4F-mediated ribosomal attachment to capped mRNAs, several eIF4F components and derivatives thereof were generated (Fig. 2A). The native eIF4E/eIF4G complex was obtained by gel filtration of eIF4F in buffer containing $1 \mathrm{M} \mathrm{KCl}$. Recombinant full-length eIF4G was expressed using a coding sequence that had been optimized to ensure correct cotranslational folding in Escherichia coli. The recombinant eIF4E/eIF4G complex was generated by coexpressing full-length eIF4G and eIF4E in E. coli. The recombinant eIF4E/eIF4G ${ }_{\Delta 1015-1104}$ complex containing eIF4G that lacked the eIF3-binding site was obtained by coexpressing eIF4G $_{\Delta 1015-1104}$ and eIF4E in E. coli. Mutant eIF4F (eIF4G $\mathrm{G}_{\Delta 1015-1104}$ ) was reconstituted from recombinant eIF4G $\mathrm{G}_{\Delta 1015-1104} / \mathrm{eIF} 4 \mathrm{E}$ and eIF4A. The activities of native and recombinant eIF4G/eIF4E were identical in all experiments described below.

\section{During eIF4F-mediated initiation, initiator $t R N A$ inspects capped $m R N A$ s from the first nucleotide}

To determine whether initiation on capped mRNAs has a "blind spot," 48S complex formation was assayed on derivatives of $\beta$-globin mRNA containing additional 5 '-terminal AUGs at different positions from the $5^{\prime}$ end (Fig. 2B). $48 \mathrm{~S}$ complexes were assembled in vitro from individual 40S subunits, Met-tRNA ${ }_{i}{ }^{\text {Met }}$, and eIFs. The ribosomal position was determined by toeprinting. Formation of $48 \mathrm{~S}$ complexes at the $\beta$-globin AUG was done in the presence of all eIFs, whereas for assembly of initiation complexes at the $5^{\prime}$-terminal codons, eIF1 was excluded. To confirm that initiation on these mRNAs depends on the eIF4E/ cap interaction, we compared $48 \mathrm{~S}$ complex formation on capped and uncapped mRNAs at different concentrations of eIF4F. Efficient 48S complex formation at the $\beta$-globin AUG of capped mRNAs occurred at much lower eIF4F concentrations than on uncapped mRNAs (shown for 2nucleotide [nt] $\beta$-globin mRNA in Fig. 2C), indicating that it was strongly stimulated by the eIF4E/cap interaction. In all further experiments, eIF4F was used at the concentration $60 \mathrm{nM}$ (except where otherwise stated in the figures and figure legends), which allows efficient 48S complex formation only on capped mRNAs.

Like at the $\beta$-globin AUG (Fig. 2D, lanes 5,10,15,20), efficient eIF4F-mediated $48 \mathrm{~S}$ complex formation at the $5^{\prime}$ terminal AUGs occurred only on capped mRNAs (Fig. 2D, lanes 4,9,14,19). Moreover, 48S complexes formed even at the AUG located at the very 5' end of 0-nt AUG$\beta$-globin mRNA. However, because of the low transcription yield of this mRNA /due to the adenine at the first position), further experiments were routinely done using 2nt AUG- $\beta$-globin mRNA. $48 \mathrm{~S}$ complex formation at $\beta$-globin and $5^{\prime}$-terminal AUGs was inhibited by $\mathrm{m}^{7} \mathrm{GTP}$ and excess eIF4E (Fig. 2E,F) and almost did not occur in reaction mixtures containing full-length eIF4G but lacking eIF4E (Fig. 2G,H), further confirming that, in both cases, initiation involved the eIF4E/cap interaction.

However, since the possibility that mechanisms of ribosomal attachment in the presence and absence of eIF1 might differ could not be ruled out, we investigated whether initiation at the $5^{\prime}$-terminal AUGs could also be stimulated by the eIF4E/cap interaction in eIF1's presence. For this, reaction mixtures were supplemented with 60S subunits, eIF5, and eIF5B to permit subunit joining. Formation of stable $80 \mathrm{~S}$ ribosomes would compete with dissociation of $48 \mathrm{~S}$ complexes by eIF1, allowing initiation at the $5^{\prime}$ end (Pestova and Kolupaeva 2002; Pestova et al. 2008). In these conditions, ribosomal complexes did form at the 5'-terminal AUG but, again, only on capped mRNA (Fig. 2I, cf. lanes 4 and 8). Thus, initiation at the 5 '-terminal AUGs was stimulated by the eIF4E/cap interaction irrespective of the presence of eIF1. To verify that eIF4F-mediated initiation at the 5'-terminal AUGs follows the "first AUG" rule, we used mRNAs containing two consecutive AUGs located 1 or 4 nt from the $5^{\prime}$ end (Fig. 2B). In both cases, 48S complexes formed only at the first codon, and initiation was much more efficient when it was mediated by eIF4F than by eIF4G/eIF4A (Fig. 2J), confirming that eIF4F-mediated initiation at 5'terminal AUGs did not occur by backward scanning.

In conclusion, eIF4F-mediated initiation on capped mRNAs does not have a "blind spot," and initiator tRNA inspects mRNA from the first nucleotide, enabling $48 \mathrm{~S}$ complexes to form at the very $5^{\prime}$ end of mRNA.

The role of the eIF4E-eIF4Gs $\bullet$ IF4A-eIF3 chain of interactions in initiation on capped $m R N A s$

Next, we investigated how the breaking of any link in the eIF4E-eIF4G•eIF4A-eIF3 chain of interactions would affect initiation on capped mRNAs. To assay the role of the eIF4E-eIF4G link, we compared the influence of eIF4E on initiation on capped and uncapped mRNAs mediated by the N-terminally truncated eIF4G ${ }_{653-1599}$ lacking the eIF4E-binding site, which was shown to promote initiation on uncapped mRNAs (e.g., Ohlmann et al. 1996). eIF4E specifically inhibited 48 S complex formation at both $\beta$-globin and 5 -terminal AUGs of 2 -nt AUG- $\beta$ - 
A

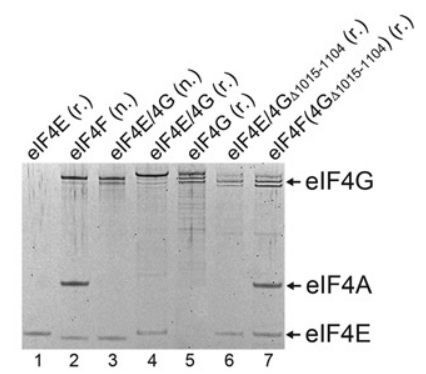

C 2nt-AUG- $\beta$-globin +++++++

cap-2nt-AUG- $\beta$-globin $\quad+++++++$

40S, elFs 3/2/1/1A/4A/4B ++++++++++++

elF4F(nM) O $4080160240320 \quad 0 \quad 1020406080$

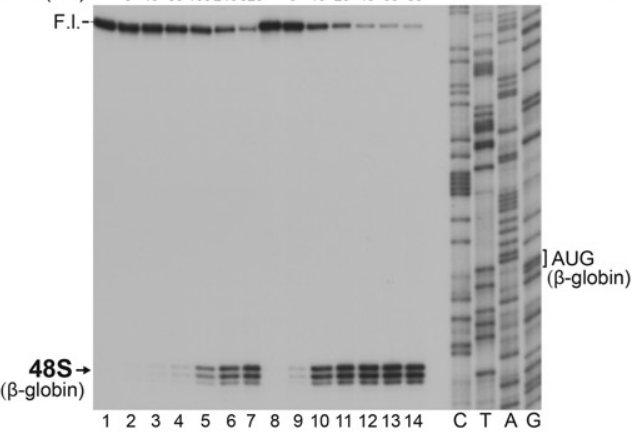

E

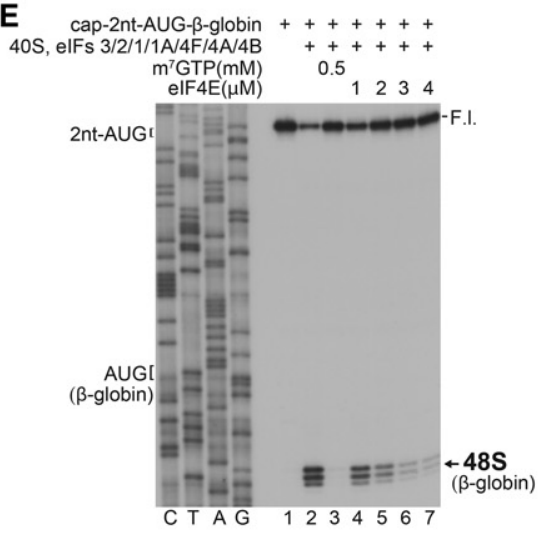

H 2nt-AUG- $\beta$-globin +++++

cap-2nt-AUG- $\beta$-globin $\quad+++++$

40S, elFs $3 / 2 / 1 \mathrm{~A} / 4 \mathrm{~A} / 4 \mathrm{~B}++++++++$
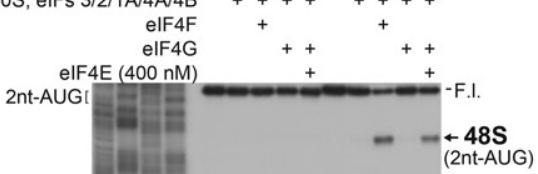

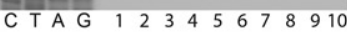

$J$

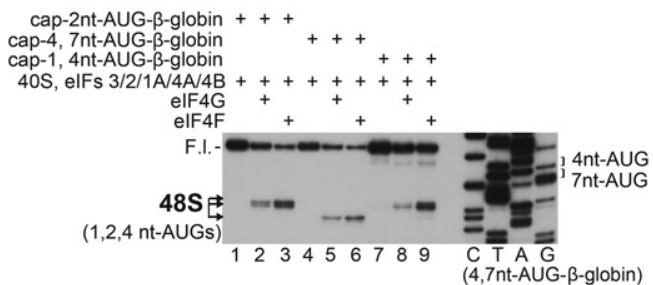

B

\section{D}

\section{$\mathbf{F}$}

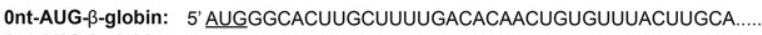
2nt-AUG- $\beta$-globin: 5' GA-AUG-GACUUGCUUUUGACACAACUGUGUUUACUUGCA....

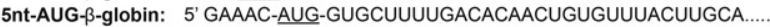

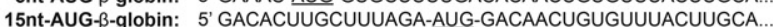
1, 4nt-AUG- $\beta$-globin: 5' G-AUGAUG-GUUGCUUUUGACACAACUGUGUUUACUUGCA... 4, 7nt-AUG- $\beta$-globin: 5 ' GACA-AUGAUG-GCUUUUGACACAACUGUGUUUACUUGCA.....

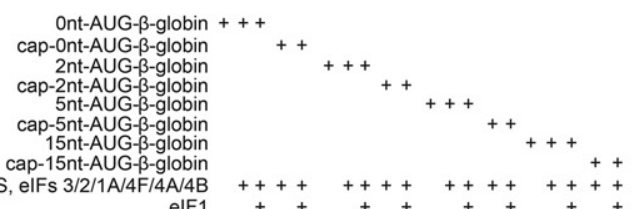

0S, elFs $3 / 2 / 1 \mathrm{~A} / 4 \mathrm{~F} / 4 \mathrm{~A} / 4 \mathrm{~B} \quad+++++++++++++++$

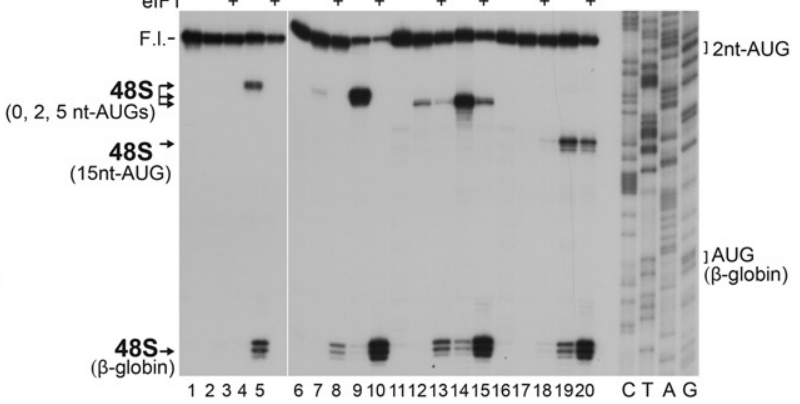

$1234567891011121314151617181920 \quad$ C T A G

cap-2nt.AUG- $\beta$-globin +++++++ 40S, elFs $3 / 2 / 1 \mathrm{~A} / 4 \mathrm{~F} / 4 \mathrm{~A} / 4 \mathrm{~B}++++++$ $\mathrm{m}^{7} \mathrm{GTP}(\mathrm{mM})$

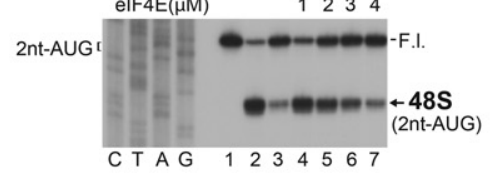

G 2nt-AUG- $\beta$-globin +++++ cap-2nt-AUG- $\beta$-globin $\quad+++++$ $\begin{array}{rcc}40 \mathrm{~S}, \text { elFs 3/2/1/1A } / 4 \mathrm{~A} / 4 \mathrm{~B} & ++++ \\ \text { elF4F } & ++ & ++ \\ + & ++\end{array}$

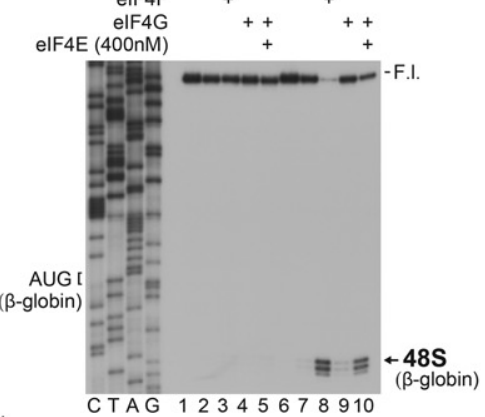

I cap-2nt-AUG- $\beta$-globin $\quad++++$ CTAG 12345678910 48S 2nt-AUG- $\beta$-globin ++++
$40 \mathrm{~S}$, elFs $3 / 2 / 1 \mathrm{~A} / 4 \mathrm{~F} / 4 \mathrm{~A} / 4 \mathrm{~B} \quad++++++$ 60 S, elFs 5/5B ++++

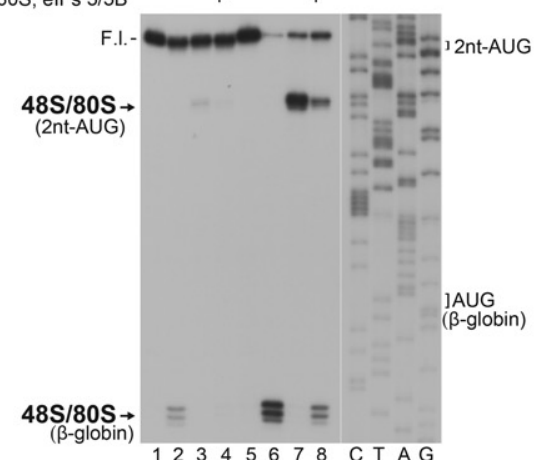

1233456678 C T A G

Figure 2. eIF4F-mediated initiation on AUG codons located at the $5^{\prime}$ end of capped mRNAs. (A) Purified native (n.) and recombinant (r.) eIF4F components and derivatives thereof resolved by SDS-PAGE. (B) $5^{\prime}$-terminal regions of capped and uncapped derivatives of $\beta$-globin mRNA showing additional AUGs at various positions from the $5^{\prime}$ end. $(C-J) 48 \mathrm{~S}(C-I)$ and $80 \mathrm{~S}(I)$ complex formation on derivatives of $\beta$ globin mRNA containing additional $5^{\prime}$-terminal AUGs (shown in $B$ ) in the presence of ribosomal subunits, Met-tRNA ${ }_{i}{ }^{M e t}$, and the indicated eIFs, assayed by toeprinting. Some reaction mixtures in $E$ and $F$ contained $\mathrm{m}^{7} \mathrm{GTP}$ as a competitor. The positions of AUG codons, full-length cDNAs (F.L.), and toeprints corresponding to $48 \mathrm{~S}$ and $80 \mathrm{~S}$ complexes are indicated. 
globin mRNA if the mRNA was capped, and inhibition was relieved by $\mathrm{m}^{7} \mathrm{GTP}$ (Fig. 3A,B). Thus, when eIF4E was not coupled with $43 \mathrm{~S}$ complexes through interaction with eIF4G, its binding to the cap had an inhibitory effect similar to that caused by association of cap0 mRNAs with IFIT1 (Kumar et al. 2014). The inhibition was stronger in the case of the $5^{\prime}$-terminal AUG. One of the potential reasons is the greater efficiency/rate of $48 \mathrm{~S}$ complex formation in the presence of eIF1, which would make eIF1mediated initiation more competitive with the excess of eIF4E, leading to a higher level of initiation on the $\beta$-globin AUG.

Next, we assayed the influence of eIF4E/eIF4G on 48S complex formation on capped mRNAs that occurred in the absence of eIF4A. For this, we used 2-nt AUG-(CAA) n-GUS mRNA comprising an unstructured 5' - UTR (consisting of CAA repeats and a $5^{\prime}$-terminal AUG) and the GUS coding region (Fig. $3 \mathrm{C}$ ), on which initiation can proceed without group 4 eIFs (Pestova and Kolupaeva 2002). In such conditions, eIF4E/eIF4G specifically inhibited 48S complex formation at both AUGs if mRNA was capped (Fig. 3D,E [cf. lanes 2 and 5], F [cf. lanes 3 and 6, and lanes 10 and 13]). Thus, in the absence of eIF4A, the eIF4E/eIF4G complex also acted as a specific inhibitor of initiation on capped mRNAs.

To assay the role of the eIF4G/eIF3 link, we used mutant eIF4F containing eIF4G $\mathrm{G}_{\Delta 1015-1104}$ that lacked the eIF3-binding site. Consistent with the importance of the eIF4G/eIF3 interaction for $5^{\prime}$ end-mediated initiation (Hinton et al. 2007), eIF4F(eIF4G $\mathrm{G}_{\Delta 1015-1104}$ ) did not support $48 \mathrm{~S}$ complex formation on $\beta$-globin mRNA (Fig. 3G). However, it was able to promote initiation on the encephalomyocarditis virus internal ribosomal entry site (EMCV IRES) (Fig. 3H), for which the eIF4G-eIF3 interaction is not essential (Lomakin et al. 2000), confirming the biochemical functionality of the factor. On 2-nt AUG(CAA)n-GUS mRNA, eIF4F(eIF4G $\left.{ }_{\Delta 1015-1104}\right)$ specifically inhibited 48S complex formation when mRNA was capped (Fig. 3I, lane 7).

We also found that $48 \mathrm{~S}$ complex formation at the $5^{\prime}$-terminal AUG of 2-nt AUG-(CAA)n-GUS mRNA could occur in the presence of only eIF2, eIF1, and eIF1A (Fig. 4A,B, lanes 7), which allowed us to evaluate the effect of wild-type eIF4F on initiation in the absence of the eIF3eIF4G interaction. In these conditions, wild-type eIF4F also specifically inhibited initiation on capped 2-nt AUG-(CAA)n-GUS mRNA (Fig. 4A,B, cf. lanes 9). To determine eIF4A's contribution, we assayed its influence on inhibition of $48 \mathrm{~S}$ complex formation by eIF4E/eIF4G. eIF4A increased inhibition in an ATP-dependent manner (Fig. 4C, cf. lanes 4 and 5, and lanes 7 and 8), likely due to stimulation of interaction of eIF4E/eIF4G with the cap, evident from increased UV cross-linking of eIF4E with the $\left[{ }^{32} \mathrm{P}\right]$ cap-labeled model mRNA (by $~ 50 \%$, on average, for the used concentrations of components) (Fig. 4D). Thus, in the absence of eIF3 or when the eIF4G/ eIF3 link cannot be established, even eIF4F specifically inhibits initiation on capped mRNAs. eIF3-independent 48S complex formation was also inhibited by eIF4E alone (Fig. 4E).
The ability of eIF2, eIF1, and eIF1A to promote $48 \mathrm{~S}$ complex formation at the $5^{\prime}$-terminal AUG indicates that the activity of eIF1 in maintaining the fidelity of initiation codon selection strongly depends on eIF3, and, in its absence, eIF1 can no longer discriminate against AUGs located too close to the $5^{\prime}$ end of mRNA. As expected, such complexes were susceptible to delayed addition of eIF3 (Fig. 4F). eIF2, eIF1, and eIF1A could also promote eIF3-independent 48S complex formation at the AUG located $28 \mathrm{nt}$ downstream from the $5^{\prime}$ end of 3AUGs(CAA)n-GUS mRNA, which was again sensitive to inhibition by eIF4F (Fig. 4G). eIF3 relieved the inhibition and yielded highly processive ribosomal complexes.

In conclusion, omission of eIF4A or disruption of any link in the eIF4E-eIF4G•eIF4A-eIF3 chain of interactions converts the eIF4E/cap association from an activator to a specific inhibitor of initiation on capped mRNAs.

\section{Specific interaction of capped $m R N A s$ with eIF3}

Next, we investigated the dynamics of the eIF4E/cap interaction. To follow this interaction, we used the UV cross-linking technique using a $\left[{ }^{32} \mathrm{P}\right]$ cap-labeled unstructured 56-nt-long model mRNA (m ${ }^{7} \mathrm{p}^{*} \mathrm{ppN}$...). However, in the course of the experiments, we found that the cap cross-linked to not only eIF4E but also an $\sim 62-\mathrm{kDa}$ subunit of eIF3 (which could correspond to eIF31 or eIF3d), and such cross-linking was inhibited by $\mathrm{m}^{7} \mathrm{GTP}$ (Fig. 5A, lanes 1,2). The uncapped body-labeled mRNA, on the other hand, more efficiently cross-linked to an $\sim 98-\mathrm{kDa}$ subunit (which could correspond to eIF3c or N-terminally truncated eIF $\Delta 3$ a) (des Georges et al. 2015), and cross-linking of this subunit was not sensitive to $\mathrm{m}^{7} \mathrm{GTP}$ (Fig. 5A, lanes 3,4$)$. The $\sim 62-\mathrm{kDa}$ subunit cross-linked to both cap0 and cap1 mRNAs (Fig. 5B).

To identify the cap-interacting subunit of eIF3, we used eIF3d-deficient and eIF3l/eIF3k-deficient eIF3 variants (Fig. 5C, top panel) that were obtained as by-products during purification of the native factor (see the Materials and Methods). $\left[{ }^{32} \mathrm{P}\right]$ cap-mRNA cross-linked to eIF3d-deficient but not eIF31/eIF3k-deficient eIF3 (Fig. 5C, bottom panel, lanes 1,2), indicating that the cap interacts with eIF31. eIF3k and eIF31 bind to each other via a large surface and form a separate lobe ("right leg") in eIF3's five-lobed PCI/MPN core (des Georges et al. 2015). They were therefore coexpressed in E. coli and purified as a complex (Fig. 5D, left panel). eIF31/eIF3k alone did not cross-link with $\left[{ }^{32} \mathrm{P}\right]$ cap-mRNA (Fig. 5D, right panel, lane 2), but their addition to eIF31/eIF3k-deficient eIF3 restored cross-linking (Fig. 5D, right panel, lanes 4,5). To determine the affinity of eIF3 to capped mRNAs, we used the UV cross-linking technique because it allows specific monitoring of the eIF31/cap-mRNA interaction, which is particularly important because eIF3 contains several RNA-binding subunits. eIF3 cross-linked to the model capped mRNA with a $K_{1 / 2, a p p}$ of $\sim 51 \mathrm{nM}$ (Fig. 5E).

Next, we investigated the requirement for N7 methylation of the cap for its interaction with eIF31. Unlike eIF4E (Niedzwiecka et al. 2002) but similarly to IFIT1 (Kumar et al. 2014), eIF3l interacted efficiently with the 
Kumar et al.

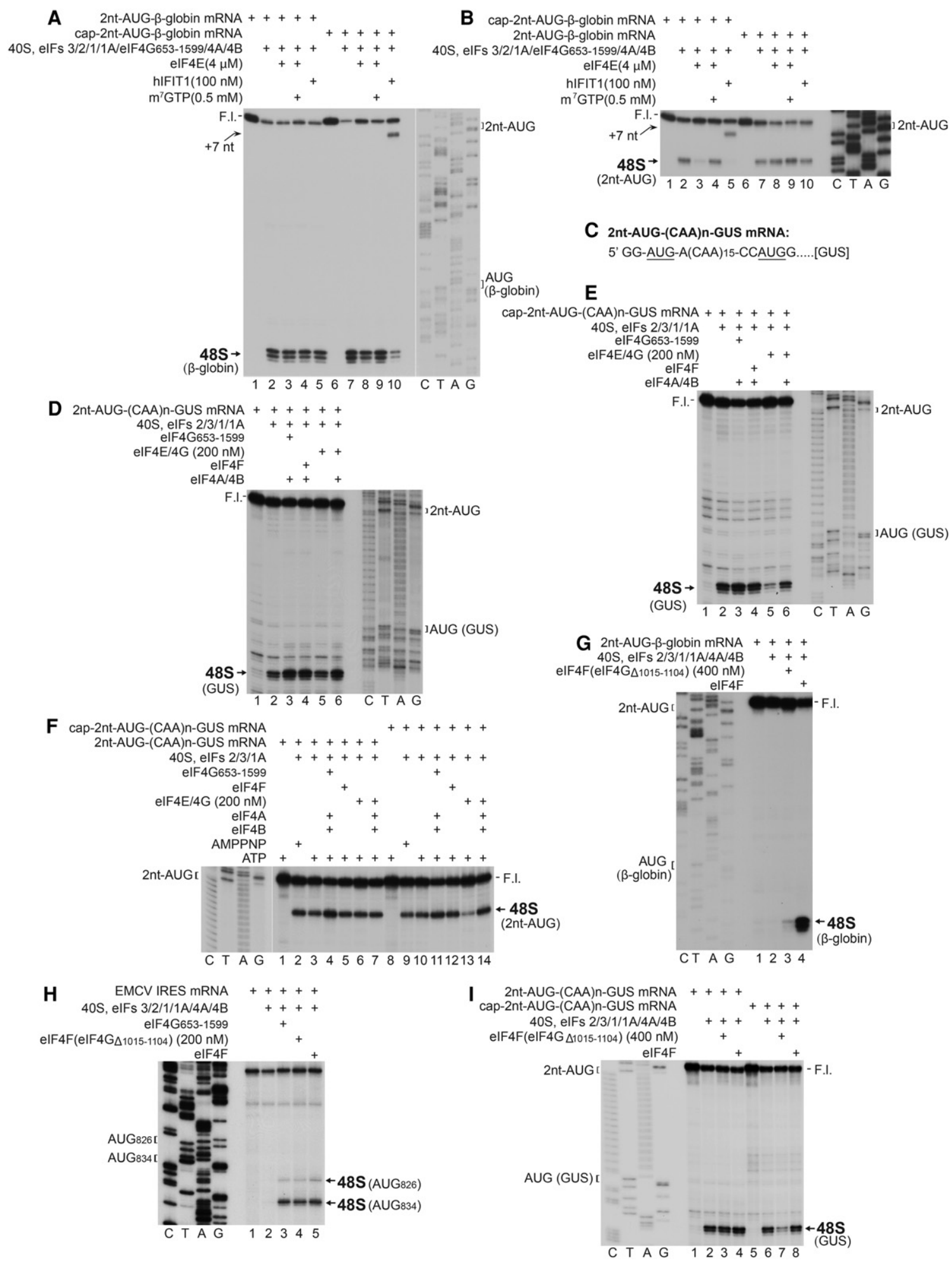

Figure 3. The influence of the eIF4E/cap interaction on 48S complex formation in conditions when eIF4E/4G or eIF4G-eIF3 links cannot be established. $(A, B, G) 48 \mathrm{~S}$ complex formation on capped or uncapped 2-nt AUG- $\beta$-globin mRNA in the presence of $40 \mathrm{~S}$ subunits, Met$\mathrm{tRNA}_{\mathrm{i}}{ }^{\mathrm{Met}}$, and the indicated eIFs, assayed by toeprinting. Some reaction mixtures contained $\mathrm{m}^{7} \mathrm{GTP}$ or IFIT1 as competitors. (C) The structure of 2-nt AUG-(CAA)n-GUS mRNA. $(D-F, I) 48 \mathrm{~S}$ complex formation on capped or uncapped 2-nt AUG-(CAA)n-GUS mRNA in the presence of $40 \mathrm{~S}$ subunits, Met-tRNA ${ }_{i}^{\text {Met }}$, and the indicated eIFs, assayed by toeprinting. $(H) 48 \mathrm{~S}$ complex formation on the encephalomyocarditis virus internal ribosomal entry site (EMCV IRES) in the presence of 40S subunits, Met-tRNA ${ }_{i}^{\text {Met }}$, and the indicated eIFs, assayed by toeprinting. The positions of AUG codons, full-length cDNAs (F.L.), reverse transcriptase stops caused by IFIT1 binding (+7 $\mathrm{nt})$, and toeprints corresponding to $48 \mathrm{~S}$ complexes are indicated. 


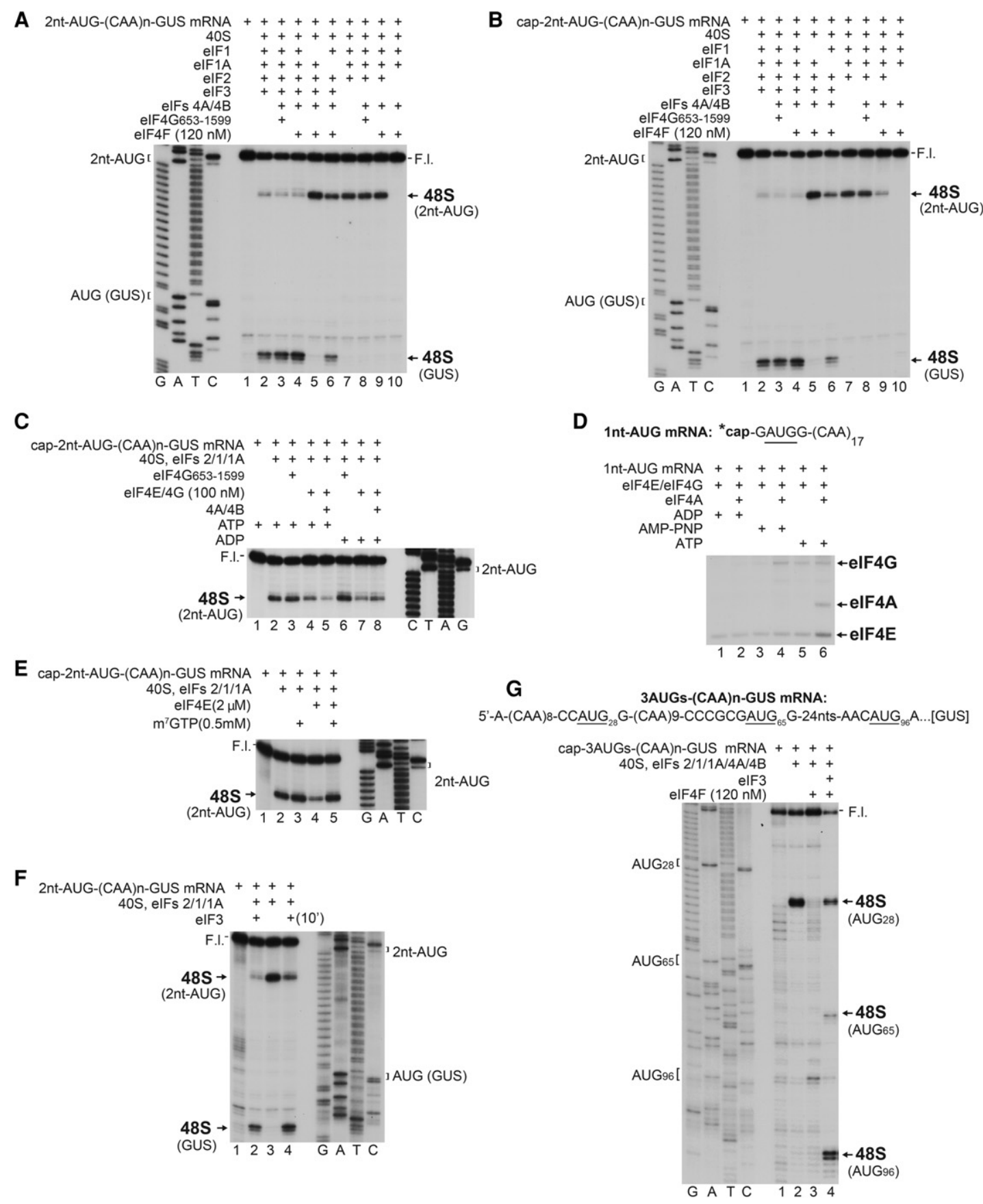

Figure 4. The influence of the eIF4E/cap interaction on $48 \mathrm{~S}$ complex formation in the absence of eIF3. $(A-C, E-G) 48 \mathrm{~S}$ complex formation on 2-nt AUG-(CAA)n-GUS $(A-C, E, F)$ and 3AUGs-(CAA)n-GUS $(G)$ mRNAs in the presence of $40 S$ subunits, Met-tRNA ${ }_{i}^{\text {Met }}$, and the indicated eIFs, assayed by toeprinting. The positions of AUG codons, full-length cDNAs (F.1.), and toeprints corresponding to 48S complexes are indicated. $(D)$ UV cross-linking of eIF4E/eIF4G to $\left[{ }^{32} \mathrm{P}\right]$ cap-GAUGG- $(\mathrm{CAA})_{17} \mathrm{mRNA}$, depending on the presence of eIF4A, ATP, AMPPNP, and ADP. The position of cross-linked eIF4E is indicated.

unmethylated cap (Fig. 5F). It could also cross-link with GTP (Fig. 5G) but not with a guanine residue when it was the first nucleotide of mRNA starting with a $5^{\prime}$-terminal ppp (ppp-G...) (Fig. 5H). Cross-linking of eIF31 with N7-methylated capped mRNA was strongly inhibited by $0.1 \mathrm{mM} \mathrm{m}^{7} \mathrm{GTP}$ or $\mathrm{m}^{7} \mathrm{GpppA}$ but less so by GTP or GDP (Fig. 5I). In titration experiments, a similar degree of inhibition required substantially higher concentrations of GTP and GpppG than of $\mathrm{m}^{7} \mathrm{GTP}$ and $\mathrm{m}^{7} \mathrm{GpppG}$ (Fig. 5J, $\mathrm{K})$. Thus, although N7 methylation was not essential, it contributed to the affinity of interaction. $\mathrm{m}^{7} \mathrm{G}$ did not inhibit cross-linking even at the concentration of $0.5 \mathrm{mM}$ (Fig. 5L), suggesting that binding also involves interaction with the ppp bridge. 

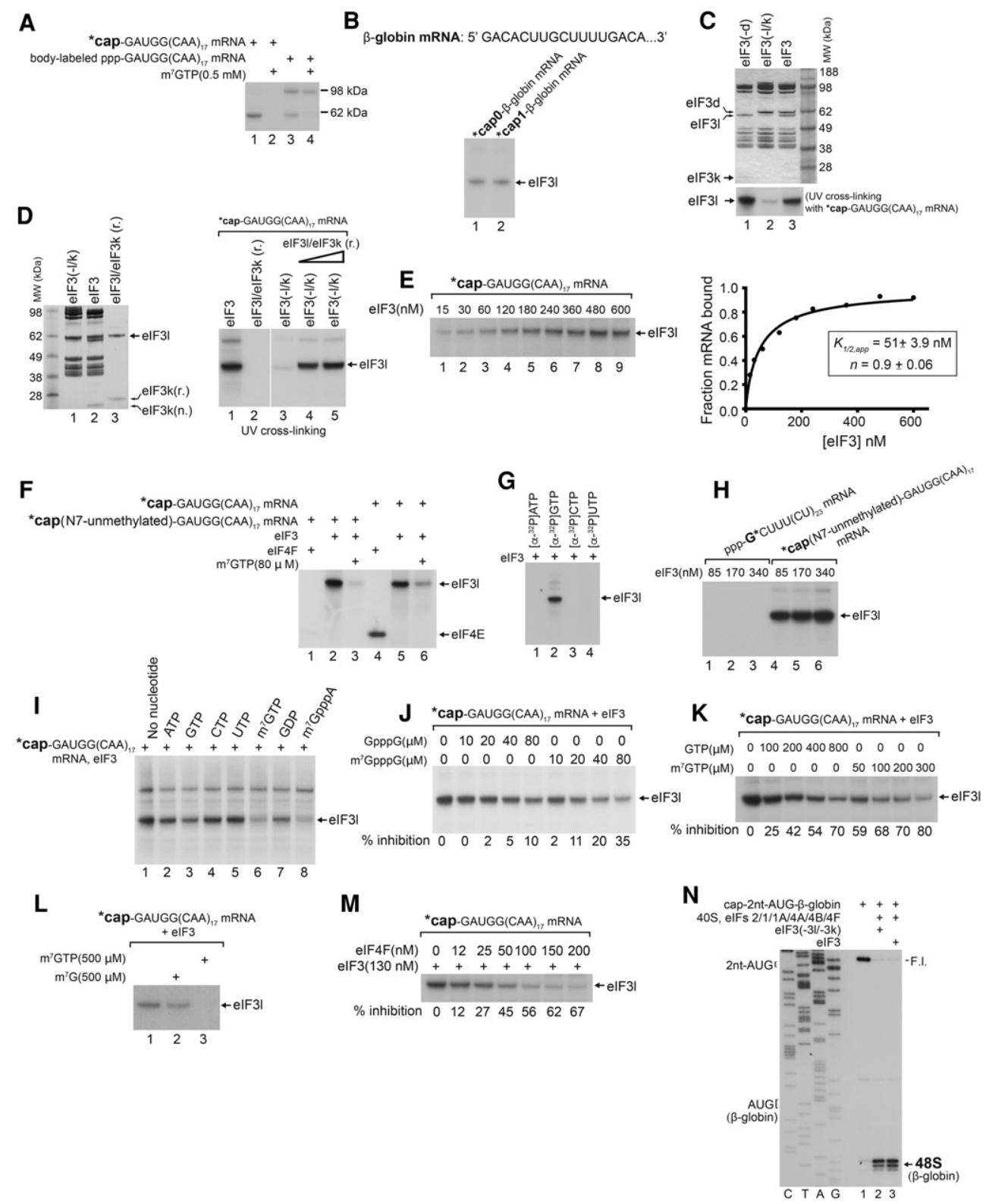

Figure 5. Specific interaction of the cap with eIF31. (A) UV cross-linking of [ $\left.{ }^{32} \mathrm{P}\right]$ cap-GAUGG- $(\mathrm{CAA})_{17}$ and body-labeled ppp-GAUGG$(\mathrm{CAA})_{17}$ mRNAs with eIF3 in the presence and absence of $\mathrm{m}^{7} \mathrm{GTP}$. $(B)$ UV cross-linking of $\left[{ }^{32} \mathrm{P}\right]$ cap0- $\beta$-globin and $\left[{ }^{32} \mathrm{P}\right]$ cap $1-\beta$-globin mRNAs with eIF3. (C) Intact, eIF3d-deficient, and eIF31/eIF3k-deficient eIF3 resolved by SDS-PAGE (top panel) and their cross-linking with $\left[{ }^{32} \mathrm{P}\right]$ cap-GAUGG-(CAA) ${ }_{17}$ mRNA (bottom panel). The positions of eIF3d, eIF31, and eIF3k subunits are indicated at the left. $(D)$ Intact, eIF31/eIF3k-deficient eIF3, and recombinant eIF31/eIF3k resolved by SDS-PAGE (left panel) and their cross-linking with $\left[{ }^{32} \mathrm{P}\right] \mathrm{cap}-$ GAUGG-(CAA) ${ }_{17}$ mRNA individually and in combination, as indicated (right panel). (E, left panel) Representative gel of titration of binding of eIF3 with $\left[{ }^{32} \mathrm{P}\right]$ cap-GAUGG- $(\mathrm{CAA})_{17} \mathrm{mRNA}$, assayed by UV cross-linking. (Right panel) Corresponding plot of the dependence of the fraction of cross-linked eIF31 on the concentration of eIF3. The curve was fitted to the nonlinear Hill equation $\left\{\right.$ Frac ${ }^{\text {(bound })}=\left(\mathrm{eIF}^{\mathrm{n}}\right)^{\mathrm{n}} \times$ Frac $\left.{ }^{\text {(bound) }}{ }_{\max } /\left[(\mathrm{eIF} 3)^{\mathrm{n}}+K^{n}{ }_{1 / 2, a p p}\right]\right\}$ using GraphPad Prism software. The dissociation constant $\left(K_{1 / 2, a p p}\right)$ and Hill coefficient $(n)$ calculated on the basis of at least three independent experiments are shown in the inset box. $(F)$ UV cross-linking of N7-methylated and unmethylated $\left[{ }^{32} \mathrm{P}\right]$ cap-GAUGG- $(\mathrm{CAA})_{17} \mathrm{mRNAs}$ to eIF3 and eIF4F in the presence and absence of $\mathrm{m}^{7} \mathrm{GTP}$. The positions of cross-linked eIF4E and eIF31 are indicated. $(G)$ Cross-linking of eIF3 with $\left[\alpha-{ }^{32} \mathrm{P}\right] \mathrm{ATP},\left[\alpha-{ }^{32} \mathrm{P}\right] \mathrm{GTP},\left[\alpha-{ }^{32} \mathrm{P}\right] \mathrm{CTP}$, and $\left[\alpha-{ }^{32} \mathrm{P}\right] \mathrm{UTP}$. The position of cross-linked eIF31 is indicated. $(H)$ UV cross-linking of unmethylated $\left[{ }^{32} \mathrm{P}\right]$ cap-GAUGG- $(\mathrm{CAA})_{17}$ and $\left[{ }^{32} \mathrm{P}\right] \mathrm{pppG}$-CUUU- $(\mathrm{CU})_{23}$ mRNAs with eIF3. The position of cross-linked eIF31 is indicated. (I) UV cross-linking of $\left[{ }^{32} \mathrm{P}\right]$ cap-GAUGG-(CAA) 17 mRNA with eIF3 in the presence or absence of $0.1 \mathrm{mM}$ different nucleotides, as indicated. The position of cross-linked eIF3l is shown at the right. $(J, K)$ Competition of $\left[{ }^{32} \mathrm{P}\right]$ cap-GAUGG- $(\mathrm{CAA})_{17}$ mRNA with GpppG and $\mathrm{m}^{7} \mathrm{GpppG}(J)$ and GTP and $\mathrm{m}^{7} \mathrm{GTP}(K)$ for binding to eIF3, assayed by UV cross-linking. Cross-links corresponding to eIF31 were quantified relative to those observed in the absence of competitors, which were defined as $100 \%$. $(L)$ The influence of $\mathrm{m}^{7} \mathrm{GTP}$ and $\mathrm{m}^{7} \mathrm{G}$ on UV cross-linking of $\left.{ }^{32} \mathrm{P}\right]$ cap-GAUGG- $(\mathrm{CAA})_{17} \mathrm{mRNA}$ with eIF3. The position of cross-linked eIF31 is indicated. (M) Competition of eIF3 with eIF4F for binding to $\left[{ }^{32} \mathrm{P}\right]$ cap-GAUGG- $(\mathrm{CAA})_{17}$ mRNA, assayed by UV cross-linking. Cross-links corresponding to eIF31 were quantified relative to those observed in the absence of eIF4F, which was defined as $100 \%$. (N) 48S complex formation on capped 2-nt AUG- $\beta$-globin mRNA in the presence of $40 \mathrm{~S}$ subunits, Met-tRNA ${ }_{i}{ }^{\text {Met }}$, and various eIFs, assayed by toeprinting. The positions of AUG codons, full-length cDNAs (F.L.), and toeprints corresponding to $48 \mathrm{~S}$ complexes are indicated. 
eIF4F competed efficiently with eIF31 for binding to capped mRNA (Fig. 5M). We also did not observe a significant difference in eIF4F-mediated 48S complex formation on 2-nt $\beta$-globin mRNA when it was mediated by intact or eIF3l/eIF3k-deficient eIF3 (Fig. 5N). However, it cannot be excluded that mRNAs have different affinities to eIF3l and that the eIF3-cap interaction could play a regulatory role in the translation of specific mRNAs possessing higher affinity to eIF3.

\section{eIF4E/cap interaction in assembled 485 complexes}

To determine whether the cap remains associated with eIF4E in 48S complexes, we first assayed complexes formed at the $5^{\prime}$-terminal AUG in the absence of eIF1. For this, we used a $\left[{ }^{32} \mathrm{P}\right]$ cap-labeled 56-nt-long unstructured mRNA containing an AUG located $1 \mathrm{nt}$ down- stream from the $5^{\prime}$ end (Fig. 6A, top panel). Sequestration of mRNA into $48 \mathrm{~S}$ complexes almost abrogated eIF4E/cap cross-linking (Fig. 6A, cf. lanes 2 and 3-5), indicating that the cap was no longer associated with eIF4F. Addition of eIF1 modestly enhanced cross-linking of eIF4E and strongly increased cross-linking of $\sim 62-\mathrm{kDa}$ and $\sim 98$ $\mathrm{kDa}$ subunits of eIF3 (Fig. 6A, lanes 6-7). In the presence of eIF1, mRNA enters the 40 S subunit, but Met-tRNA ${ }_{i}^{\text {Met }}$ is not able to base-pair with the $5^{\prime}$-terminal AUG, and the position of mRNA in the mRNA-binding channel is therefore not fixed. In these circumstances, cross-linking of the cap would be determined by the position of mRNA in the most stable complexes that could form in the absence of codon-anti-codon base-pairing. Based on the pattern of mRNA cross-linking in $48 \mathrm{~S}$ complexes (Pisarev et al. 2008 ), the $\sim 62-\mathrm{kDa}$ and $\sim 98-\mathrm{kDa}$ cross-linked proteins most likely corresponded to eIF3d and eIF $\Delta 3 \mathrm{a} / \mathrm{eIF} 3 \mathrm{c}$,
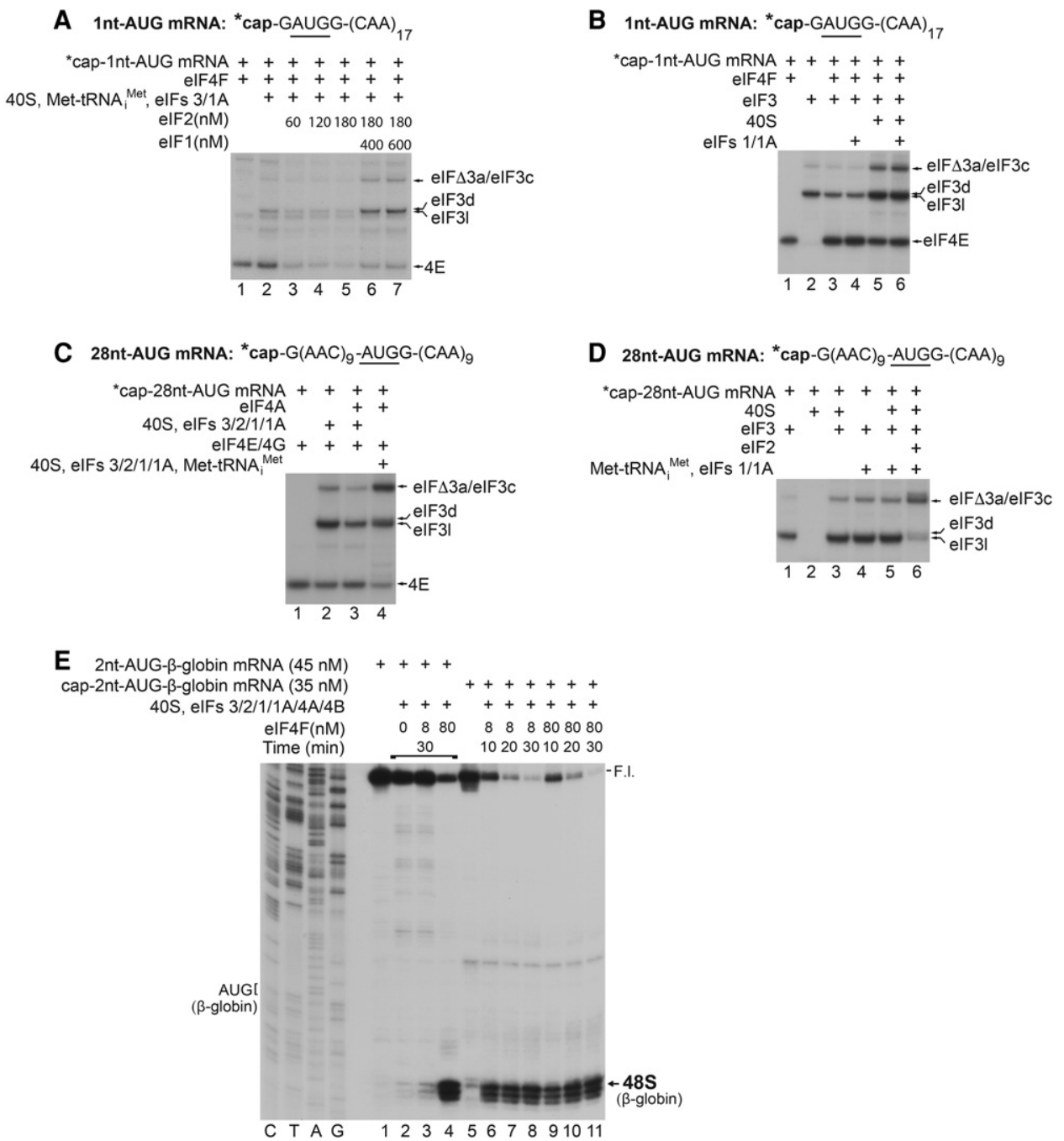

Figure 6. Interaction of eIF4E with the cap in $48 \mathrm{~S}$ complexes. $(A-D)$ UV cross-linking of $\left[{ }^{32} \mathrm{P}\right]$ cap-GAUGG- $(\mathrm{CAA}){ }_{17}(A, B)$ and $\left[{ }^{32} \mathrm{P}\right] \mathrm{cap}-\mathrm{G}$ $(\mathrm{AAC})_{9}$-AUGG- $(\mathrm{CAA})_{9}(C, D)$ mRNAs with translational components in reaction mixtures containing $40 \mathrm{~S}$ subunits, Met-tRNA ${ }_{\mathrm{i}}{ }^{\text {Met }}$, and eIFs, as indicated. The identities of cross-linked proteins are shown at the right. (E) Time course of $48 \mathrm{~S}$ complex formation on 2-nt AUG- $\beta$ globin mRNA depending on the concentration of eIF4F. Reaction mixtures contained 40S subunits, Met-tRNA ${ }_{i}{ }^{\text {Met }}$, and eIFs, as indicated. The positions of AUG codons, full-length cDNAs (F.L.), and toeprints corresponding to 48S complexes are shown. 
respectively, indicating that, in ribosomal complexes formed in the presence of eIF1, the $5^{\prime}$ end of mRNA had exited the mRNA-binding channel. The same pattern of cross-linking was observed in the absence of eIF2-TC (Fig. 6B, lanes 5,6). We note that, in similar conditions, ssRNA, eIF3, and a 40S subunit could form a stable ternary complex in which RNA is accommodated in the channel (Kolupaeva et al. 2005).

When AUG was located $28 \mathrm{nt}$ downstream from the $5^{\prime}$ end (Fig. 6C, top panel), sequestration of mRNA into $48 \mathrm{~S}$ complexes also substantially reduced eIF4E/cap cross-linking (Fig. 6C, cf. lanes 4 and 1-3). In this case, the strongest cross-link occurred with the $\sim 98-\mathrm{kDa}$ protein corresponding to eIF3c/eIF $\Delta 3 \mathrm{a}$, which is consistent with cross-linking of mRNA at a similar " -26 " position (Pisarev et al. 2008). The analogous cross-linking pattern was observed in 48S complexes assembled in the absence of eIF4F (Fig. 6D, lane 6). These results are also consistent with dissociation of the eIF4E/cap interaction in $48 \mathrm{~S}$ complexes. In addition, they indicate that the length of mRNA that emerges from the $40 \mathrm{~S}$ subunit in $48 \mathrm{~S}$ complexes assembled at the AUG located $28 \mathrm{nt}$ from the $5^{\prime}$ end is not sufficient for the cap to bind eIF4E de novo.

We next investigated whether eIF4F can entirely dissociate from the $48 \mathrm{~S}$ complex and mediate multiple initiation cycles. On capped 2-nt $\beta$-globin mRNA, 8 nM eIF4F promoted nearly quantitative $48 \mathrm{~S}$ complex formation on $\sim 35 \mathrm{nM}$ mRNA, indicating that eIF4F had participated in four rounds of initiation (Fig. 6E). The kinetics of $48 \mathrm{~S}$ complex formation in the presence of 8 and $80 \mathrm{nM}$ eIF4F was similar, suggesting that the limiting step was formation of $43 \mathrm{~S}$ complexes rather than their attachment to mRNA and scanning. However, regarding the slow rate of $48 \mathrm{~S}$ complex formation, it is possible that eIF4F was not actively "released" from assembled 48S complexes but instead dissociated spontaneously and that functional "release" of eIF4F would in fact require ribosomal subunit joining.

\section{eIF4F-mediated $48 S$ complex formation on uncapped $m R N A s$}

The results of our experiments suggest that, during eIF4Fmediated ribosomal attachment to capped mRNAs, eIF4E has to be correctly positioned by the eIF4E-eIF4G-eIF340 S chain of interactions but, at some stage, would likely have to disengage from the cap to prevent steric hindrance during accommodation of mRNA in the mRNA-binding channel. If the placement of eIF4E facilitates entry of capped mRNA into the channel, uncapped mRNAs might by default follow the same "eIF4E-through" path during eIF4F-mediated initiation. To investigate this possibility, we assayed the influence of $\mathrm{m}^{7} \mathrm{GTP}$ on initiation on uncapped 2-nt $\beta$-globin mRNA. Strikingly, $\mathrm{m}^{7} \mathrm{GTP}$ nearly abrogated 48S complex formation at the $\beta$-globin AUG when the process was mediated by eIF4F but not eIF4A/ eIF4G ${ }_{653-1599}$, and this effect did not depend on the identity of the first mRNA nucleotide (Fig. 7A). $\mathrm{m}^{7} \mathrm{GTP}$ also inhibited eIF4F-mediated 48S complex formation at the $5^{\prime}$ terminal AUG (Fig. 7B, lane 3). In control experiments, initiation on both AUGs was not inhibited by eIF4E (Fig. 7B, lanes 4-7,10-13). eIF4F-mediated 48S complex formation on uncapped 2-nt $\beta$-globin mRNA was also inhibited by $\mathrm{m}^{7} \mathrm{GpppA}$ but not $\mathrm{m}^{7} \mathrm{G}$ (Fig. $7 \mathrm{C}$ ).

Inhibition of $48 \mathrm{~S}$ complex formation by $\mathrm{m}^{7} \mathrm{GTP}$ was not due to reduction of eIF4F's helicase activity because the same degree of unwinding of an RNA duplex comprising an overhanging 25-nt-long 5' end and a 13-nt-long double-stranded region $(\Delta \mathrm{G}=-21 \mathrm{kcal} / \mathrm{mol})$ occurred in the presence and absence of $\mathrm{m}^{7} \mathrm{GTP}$ (Fig. 7D). Consistently, $\mathrm{m}^{7} \mathrm{GTP}$ did not inhibit eIF4F-mediated 48S complex formation on the EMCV IRES, on which ribosomal attachment occurs independently of the $5^{\prime}$ end (Fig. 7E).

We next investigated the influence of $\mathrm{m}^{7} \mathrm{GTP}$ and $\mathrm{m}^{7} \mathrm{GpppG}$ on translation of uncapped mRNAs in rabbit reticulocyte lysate (RRL). Both $\mathrm{m}^{7} \mathrm{GTP}$ and $\mathrm{m}^{7} \mathrm{GpppG}$ inhibited translation of $\beta$-globin and luciferase mRNAs, with $\mathrm{m}^{7}$ GpppG having the bigger effect (Fig. 7F, G, left panels). However, inhibition was lower than in the in vitro reconstituted system. To determine whether incomplete inhibition was due to limiting amounts of active eIF4E, in which case some initiation events would be mediated by eIF4G/ eIF4A, RRL was supplemented with eIF4E. eIF4E strongly increased inhibition by cap analogs (Fig. 7F,G, right panels). As expected, translation driven by the EMCV IRES was not sensitive to $\mathrm{m}^{7} \mathrm{GTP}$ or $\mathrm{m}^{7} \mathrm{GpppG}$ (Fig. $7 \mathrm{H}$ ).

\section{Discussion}

The mechanism of eIF4F-mediated ribosomal attachment to cellular capped mRNAs is one of the principal open questions in eukaryotic translation. The defining difference between all possible mechanisms is the way in which eIF4E-bound mRNA initially enters the mRNAbinding channel: by directly "slotting" into it over a certain length that includes the $\mathrm{P}$ site or progressively "threading" through the mRNA entrance (Fig. 1). In the first case, eIF4E would be located on the trailing side of the $40 \mathrm{~S}$ subunit, whereas in the second, it would be on the leading side. In an interesting model for the organization of the scanning complex based on the first mechanism (Marintchev et al. 2009), the cap-binding complex has limited processivity and eventually dissociates from the leading end of the mRNA but remains associated with mRNA via the eIF4E/cap interaction, leaving the 5 '-proximal region ready for ribosomal attachment. After attachment, eIF4E would be on the trailing E-site side of the 40 S subunit, whereas eIF4A would act at its leading edge, unwinding mRNA before it enters the mRNA-binding channel. The model in which eIF4E is located near the E site was initially supported by EM studies that indicated that eIF4G binds to the left arm of eIF3 and cryo-EM studies that localized this element of eIF3 in proximity to the $\mathrm{E}$ site (Siridechadilok et al. 2005). However, a recent substantial revision of eIF3's orientation on the 40 S subunit places eIF3c and eIF3e, the eIF4G-binding subunits, near the solvent side of the $40 \mathrm{~S}$ subunit, below the platform (Hashem et al. 2013; des Georges et al. 2015). The "slotting" mechanism, with the eIF4E-bound cap being at the trailing edge of the $40 \mathrm{~S}$ subunit, would imply a "blind" 
Downloaded from genesdev.cshlp.org on April 25, 2023 - Published by Cold Spring Harbor Laboratory Press

Translation initiation on capped mRNAs

\section{A}

2nt-AUG- 3 -globin(A) mRNA: 2nt-AUG- $\beta$-globin mRNA +++++ 2nt-AUG- $\beta$-globin(A) mRNA $40 \mathrm{~S}$, elFs $2 / 3 / 1 / 1 \mathrm{~A} / 4 \mathrm{~A} / 4 \mathrm{~B}$ elF4G653-1599
elF4F

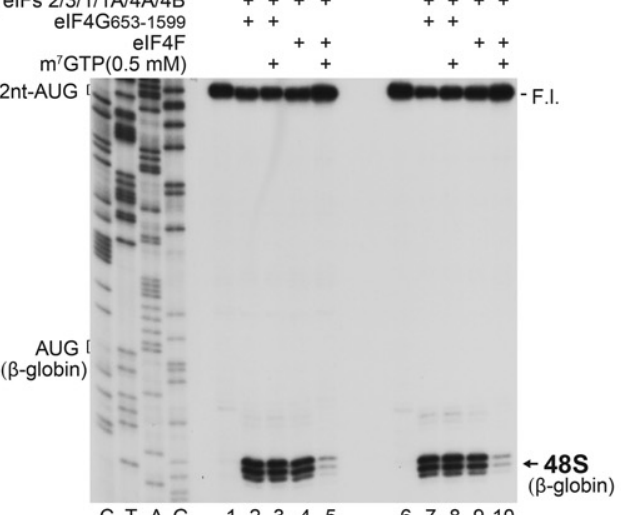

C T A G $122345 \quad 678910$

\section{C}

$\begin{array}{rrcc}\text { 2nt-AUG- } \beta \text {-globin mRNA }+++++ & 25 \mathrm{nt} & 13 \mathrm{bp} \\ \text { OS, elFs } 2 / 3 / 1 / 1 \mathrm{~A} / 4 \mathrm{~A} / 4 \mathrm{~B} / 4 \mathrm{~F} & ++++ & \text { 5'-(CAAAA) } \text { SCUGAGGACUUACG-3' }_{5} \text {, }\end{array}$

$\begin{array}{rcr}\text { 40S, elFs 2/3/1/1A/4A/4B/4F } & ++++ & 5 \text {-(CAAAA) })_{5} \text { CUGAGGACUUACG-3' } \\ \mathrm{m}^{7} \mathrm{GTP}(0.5 \mathrm{mM}) & + & +\end{array}$

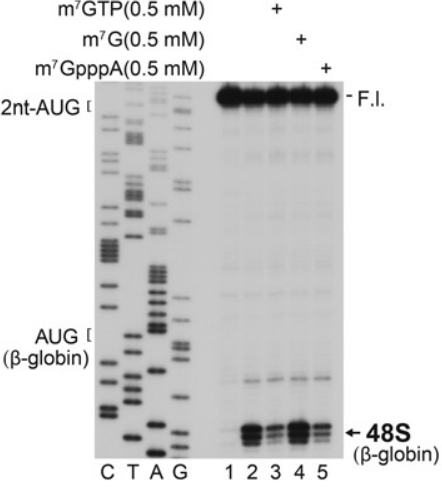

$\mathbf{F}$

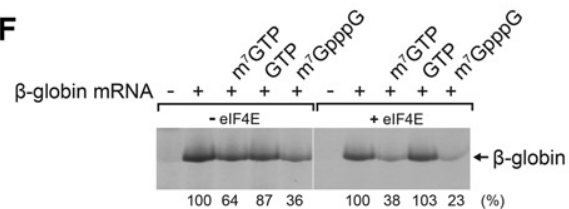

B
2nt-AUG- $\beta$-globin mRNA +++++++++++++ 40S, elFs 2/3/1A/4A/4B/4F $\quad++++++++++++$
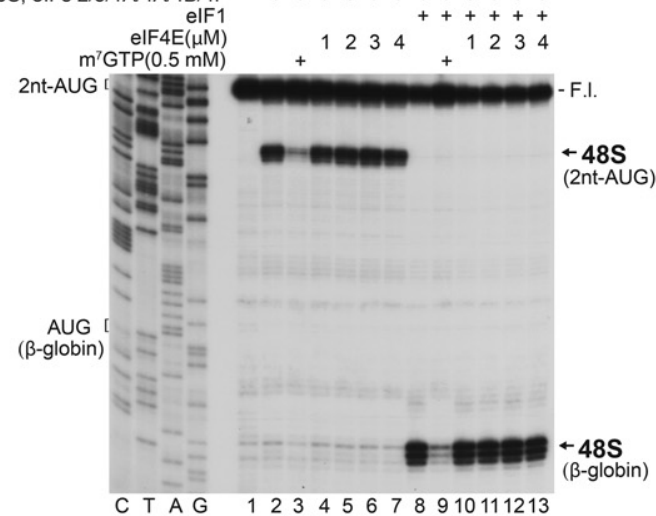

E EMCVIRES MRNA ++++++ 40S, elFs $3 / 2 / 1 / 1 \mathrm{~A} / 4 \mathrm{~A} / 4 \mathrm{~B}$, PTB $\quad+++++$ elF4G653-1599 ++
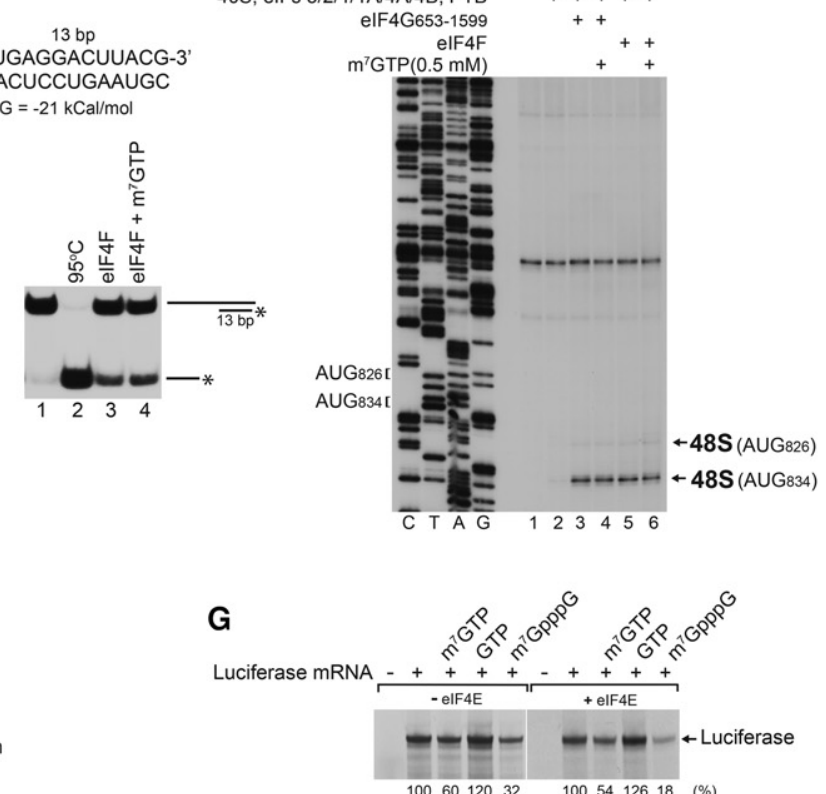

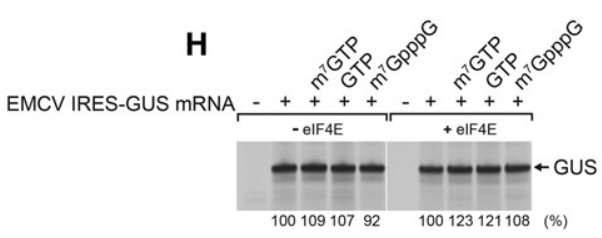

Figure 7. The influence of cap analogs on eIF4F-mediated $48 \mathrm{~S}$ complex formation on uncapped mRNAs. $(A-C, E)$ The influence of cap analogs $\left(\mathrm{m}^{7} \mathrm{GTP}, \mathrm{m}^{7} \mathrm{G}\right.$, and $\left.\mathrm{m}^{7} \mathrm{GpppA}\right)$ on $48 \mathrm{~S}$ complex formation on uncapped 2-nt AUG- $\beta$-globin (starting from either $\mathrm{G}$ or A) $(A-C)$ and EMCV IRES $(E)$ mRNAs in the presence of 40 S subunits, Met-tRNA ${ }_{i}{ }^{\text {Met }}$, and the indicated eIFs, assayed by toeprinting. The positions of AUG codons, full-length cDNAs (F.L.), and toeprints corresponding to 48S complexes are indicated. (D) Nondenaturing PAGE showing unwinding of a 13-base-pair (bp) RNA duplex with a 25-nt-long single-stranded overhanging 5'-terminal region. Mobilities of duplex RNAs and ssRNAs are indicated schematically at the right. The control for denatured strands is represented by $95^{\circ} \mathrm{C}$. $(F-H)$ The influence of $\mathrm{m}^{7} \mathrm{GTP}$ and $\mathrm{m}^{7} \mathrm{GpppG}$ cap analogs on translation of uncapped $\beta$-globin $(F)$, luciferase $(G)$, and EMCV IRES $(H)$ mRNAs in rabbit reticulocyte lysate (RRL) either supplemented or not by eIF4E. Translation products were quantified relative to those synthesized in the absence of cap analogs, which were defined as $100 \%$.

spot at the $5^{\prime}$ end of mRNA due to the inability of eIF4E to come close enough to the $\mathrm{P}$ site because of steric hindrance. Moreover, depending on the flexibility of eIF4E in 43S complexes, ribosomal attachment may occur within a defined window rather than at a specific distance from the $5^{\prime}$ end. 
However, we found that, during eIF4F-mediated initiation on capped mRNAs, Met-tRNA ${ }_{i}^{\text {Met }}$ inspected mRNA from the first nucleotide, allowing 48S complex formation at the very $5^{\prime}$ end of mRNA. Moreover, initiation at the 5'-terminal AUGs followed "the first AUG" rule, indicating that it did not occur by backward scanning (Skabkin et al. 2013; Abaeva et al. 2016). Thus, eIF4F-mediated initiation at the $5^{\prime}$ termini of capped mRNAs showed all of the characteristics of the canonical $5^{\prime}$ enddependent scanning mechanism. Similar results have been reported for initiation in the primitive eukaryote Giardia lamblia: Its mRNAs have 0- to 12-nt-long capped 5' UTRs; initiation follows the "first AUG" rule, implying that initiation codon selection involves scanning; and initiation on a model 1-nt-long 5' UTR was cap/eIF4E-dependent (Li and Wang 2004). Translation in vivo of TISU mRNA containing a 5-nt-long 5' UTR has also been reported to be cap-dependent even though, surprisingly, it was independent of eIF4A (Elfakess et al. 2011). It is difficult to imagine that eIF4E could bind at the E-site side of the mRNA-binding channel close enough to the P site to be able to deposit the $5^{\prime}$ end of mRNA directly into it, particularly in light of the ribosomal location of eIF $2 \alpha$ and its direct interactions with mRNA at the $-2 /-3$ positions (Pisarev et al. 2006; Hussain et al. 2014). It is therefore more logical to assume that eIF4E is located on the Asite side and that mRNA is threaded into the mRNA-binding channel through its entrance.

This scenario is further supported by the observation that cap analogs inhibited eIF4F-mediated initiation at the 5'-terminal AUGs of uncapped mRNAs. Thus, if eIF4E is located on the E-site side, the mRNA would not even reach eIF4E, whereas if it resides on the A-site side and uncapped mRNAs enter the mRNA-binding channel also through eIF4E, cap analogs would block initiation even at the $5^{\prime}$-terminal AUGs. However, this argument should be applied cautiously. Thus, although inhibition of initiation on uncapped mRNAs by cap analogs in cellfree extracts has been observed (Bergman and Lodish 1979; Fletcher et al. 1990), other reports indicated that they had little effect on translation of uncapped mRNAs (Canaani et al. 1976) or even enhanced it (De Gregorio et al. 1998). These differences have been ascribed to the variable presence of capped fragments of endogenous mRNAs in different nuclease-treated lysates and the strong $\left[\mathrm{K}^{+}\right]$dependence of the susceptibility to cap analog inhibition. According to our data, the difference could also arise from variations in amounts of active eIF4E and eF4Eunbound eIF4G. A further complicating factor is that some cap analogs have a nonspecific inhibitory effect on RNA-protein interactions (Sonenberg and Shatkin 1978).

The ribosomal position of the eIF4G-binding subunits of eIF3 (des Georges et al. 2015) and the sites of directed cleavage in the expansion segment $\mathrm{ES}^{\mathrm{S}}$ of $18 \mathrm{~S}$ rRNA from the 43S-bound middle domain of eIF4G (Yu et al. 2011) are not incompatible with the suggestion that eIF4F could reside on the solvent side of the 43S complex between the PCI/MPN core and the eIF3b/eIF3i/eIF3g module, with eIF4E reaching the area around the entrance of the mRNA-binding channel. However, it is more diffi- cult to reconcile our model with the finding that a region of eIF4G on the C-terminal side of the eIF4E-binding domain interacts with eIF5 (He et al. 2003), which has tentatively been located between eIF1 and eIF2 $\gamma$ on the platform of the 40S subunit (Hussain et al. 2014). However, it is difficult to comment on this issue because the structure of full-length eIF4G is not known. It is also not clear whether this potential discrepancy is relevant to initiation in mammals because the eIF4G-eIF5 interaction has been observed only in Saccharomyces cerevisiae, in which eIF4G does not interact directly with eIF3.

If eIF4E is located at the A-site side, the question arises as to the exact position at which the $5^{\prime}$ end enters the mRNA-binding channel; e.g., at the entrance to the channel, corresponding to the +15 position in mRNA, or closer to the A site (e.g., at positions +8-9), where toeprints corresponding to $48 \mathrm{~S}$ complexes were observed (Abaeva et al. 2011)? If eIF4E were located at the mRNA entrance (position +15 ), it could potentially contact the eIF3b/eIF3i/ eF3g module and DHX29, which interacts with eIF3b, bridges h16 with the beak, and, via a small domain that binds in the intersubunit space just outside the A site, also bridges the body with the beak (Hashem et al. 2013). If eIF4E resides closer to the A site, it could clash with DHX29. At high concentrations, DHX29 inhibits 48S complex formation (Pisareva et al. 2008). Thus, while DHX29 is important for scanning, it might interfere with initial attachment indirectly by inducing conformational changes in ribosomal complexes or directly by clashing with eIF4E or blocking mRNA entry.

In assembled 48S complexes, the cap was no longer cross-linked to eIF4E, which indicates that, at some stage, the eIF4E/cap interaction has to be dissolved. Consistently, cross-linking of the cap and eIF4E is inefficient in cellfree extracts (Sonenberg and Shatkin 1977; Sonenberg et al. 1979a), and it was also suggested that, during initiation, the eIF4E-cap interaction is disrupted (Sonenberg et al. 1979b). According to our model, the most likely stage at which eIF4E is released from the cap is the beginning of attachment, when dissociation would be required to avoid steric hindrance as mRNA enters the mRNAbinding channel. The most obvious implication of eIF4E/cap dissociation is that the $5^{\prime}$ end of mRNA will be able to participate immediately in the next round of initiation. Without release of the cap, the next $43 \mathrm{~S}$ complex could not be loaded until the first had reached the initiation codon and subunit joining had released factors; i.e., "cap-tethered scanning" (Berthelot et al. 2004). These investigators argued that because initiation rates did not change as a function of 5' UTR length (up to 1000 nt), scanning cannot be rate-limiting for initiation, and multiple 43S complexes must therefore be able to load onto long 5' UTRs.

Is there a trigger for the release of eIF4E from the cap and, if so, what is it? The interaction between eIF4E and eIF4G involves a conserved motif in the $\mathrm{N}$-terminal third of eIF4G that binds to the dorsal surface of eIF4E on the exterior of the cap-binding pocket (Mader et al. 1995; Gross et al. 2003). In yeast, association of eIF4E with eIF4G induces coupled conformational changes (Gross et al. 
2003), resulting in the increase of eIF4E's affinity for the cap (Gross et al. 2003). In contrast, mammalian eIF4G does not increase eIF4E's affinity for the cap (Slepenkov et al. 2008). Moreover, it has been suggested that the affinity of eIF4E for the cap is only a minor factor in the overall affinity of eIF4F for mRNA (Kaye et al. 2009). Instead, eIF4G stimulates eIF4E-cap interaction by binding to mRNA and increasing eIF4E's effective concentration in the vicinity of the cap (Yanagiya et al. 2009). The mammalian eIF4E-cap interaction has a short lifetime of $\sim 12$ msec (Slepenkov et al. 2008), and loading of mRNA into the mRNA-binding channel could therefore result from spontaneous release of the cap due to the relatively fast cycling of eIF4E between the apo- and cap-bound states. However, the possibility that the activity of eIF4A and the influence of the functional environment could contribute to triggering release of eIF4E from the cap cannot be excluded. Interestingly, it has been suggested recently that accommodation of mRNA in the mRNA-binding channel is accompanied by large conformational changes based on the observed relocation of the yeast eIF3b/eIF3i/ eF3g module from the solvent side of the 40S subunit in $43 \mathrm{~S}$ complexes to the intersubunit side in $48 \mathrm{~S}$ complexes (Llácer et al. 2015). If eIF4E has to be actively released from the cap by the concerted action of ribosome-associated eIF4A, eIF4G, and eIF3, this could explain why disruption of any link in the eIF4E-eIF4G.eIF4A-eIF3 chain of interactions converts eIF4E into a specific inhibitor of initiation on capped mRNAs.

Another implication of this model concerns the mechanism of action of group 4 eIFs during scanning. If these factors are located at the leading edge of the 40S subunit, they would most likely unwind mRNA before it enters the mRNA-binding channel. Although eIF4A for a long time was considered to be a weak helicase, recent studies have shown that, cooperatively, group 4 eIFs can unwind quite stable RNA duplexes (García-García et al. 2015). However, if eIF4A/4B/4G act at the leading edge, then what is the function of DHX29, which binds directly along the $3^{\prime}$ portion of mRNA-binding channel (Pisareva et al. 2008; Hashem et al. 2013)? Given its location and interactions, it is possible that DHX29 could induce oscillating conformational changes in the mRNA-binding channel, which would facilitate feeding into it of unwound mRNA before it has a chance to reanneal.

In the course of our experiments, we also found that, like in yeast (Maag et al. 2005), the mammalian translation apparatus can form $48 \mathrm{~S}$ initiation complexes on unstructured mRNA with only the eIF2-TC, eIF1, and eIF1A. Importantly, such complexes formed even on 5'terminal AUGs. Thus, in the absence of eIF3, eIF1 was not able to discriminate against AUGs located too close to the $5^{\prime}$ end of mRNA. We previously noted that, in the absence of eIF3, eIF1 was also unable to discriminate efficiently against formation of $48 \mathrm{~S}$ complexes at near-cognate codons during reinitiation on calicivirus mRNAs (Zinoviev et al. 2015). Taken together, this indicates that eIF3 additionally has a role in maintaining the fidelity of initiation codon selection and, with eIF1A, cooperates with eIF1 in this process.
Another interesting finding is the specific interaction of the cap with eIF3. Cross-linking of the cap (Sonenberg et al. 1979a) and the nucleotide at the +2 position from the cap (Lindqvist et al. 2008) with an eIF3 subunit of a similar molecular weight has been reported previously and was attributed to eIF3d (Lindqvist et al. 2008). We, however, identified the cap-interacting subunit as eIF31. Interaction of eF31 with the cap is consistent with the identification of eIF31 as a polypeptide that binds to the $\mathrm{m}^{7}$ GTP-sepharose (Tcherkezian et al. 2014). eIF31 does not structurally resemble eIF4E. Instead, it contains a PCI domain that consists of N-terminal helical repeats followed by a winged helix domain (Ellisdon and Stewart 2012). Notably, IFIT1, which specifically interacts with cap0 mRNAs (e.g., see Kumar et al. 2014), also has a helical structure comprising several tetratricopeptide repeat motifs (Abbas et al. 2013). Although N7 methylation enhanced the affinity of eIF3 to capped mRNA, its effect was much less pronounced than in the case of eIF4E. In this respect, eIF31 is more similar to IFIT1, whose affinity to the methylated cap was only approximately threefold to 10-fold higher than to the unmethylated cap (Kumar et al. 2014). The observation that eIF31 binds capped mRNA only after incorporation into the eIF3 holofactor suggests that, as for other cap-binding proteins (e.g., the CBP20/CPB80 heterodimer) (Mazza et al. 2002), induced conformational changes in eIF3L are required to form the cap-binding pocket. eIF3l/eIF3k reside on the periphery of eIF3's PCI/MPN core (des Georges et al. 2015) and dissociate relatively easily (Zhou et al. 2008). eIF31 is not essential for eIF3's function (Masutani et al. 2007; Morris et al. 2007). eIF31's cellular role remains uncharacterized, although, when overexpressed, it modestly represses yellow fever virus (YFV) replication (Schoggins et al. 2011), binds to the YFV RNA polymerase, and specifically inhibits YFV but not general cellular translation (Morais et al. 2014). We suggest that the eIF31/cap interaction might play a regulatory role in the translation of specific mRNAs with particularly high affinity to the factor. Both inhibition (in the case of $5^{\prime}$ end-dependent initiation) and activation (in the case of internal initiation) of translation could be envisioned. In either case, regulation would be coupled with the availability of active eIF4F. Interestingly, ribosomal profiling suggested that many mRNAs exhibit relatively modest sensitivity to chemical inhibition of mTOR, which enhances sequestration of eIF4E (Thoreen et al. 2012). Translation of at least one of these mRNAs is nevertheless sensitive to inhibition by cap analogs, suggesting that it might use an alternative mechanism of capdependent initiation, potentially involving binding by eIF3 (Lee et al. 2015).

In conclusion, although our data are most consistent with the model in which eIF4E is located at the leading edge of the 40S subunit and mRNA is threaded into the mRNA-binding channel through the entrance, structural determination of the position of eIF4F and, in particular, its eIF4E subunit in the eIF4F-bound 43S complex is required to establish a more conclusive model for the mechanism of eF4F-mediated ribosomal attachment to mammalian capped mRNAs. 


\section{Materials and methods}

Plasmid construction; purification of ribosomal subunits, initiation factors, and methionyl tRNA synthetase; preparation of mRNAs and tRNA ${ }_{i}^{\text {Met }}$; mRNA capping; and aminoacylation of tRNA $_{i}{ }^{\text {Met }}$ are described in the Supplemental Material, which also contains detailed protocols for all experimental procedures.

\section{Assembly and analysis of 48S/80S initiation complexes}

$48 \mathrm{~S}$ complexes were assembled on capped or uncapped derivatives of $\beta$-globin and (CAA)n-GUS mRNAs as well as mRNA containing the EMCV IRES and analyzed by toeprinting. Briefly, mRNA was incubated for $10 \mathrm{~min}$ at $37^{\circ} \mathrm{C}$ with $40 \mathrm{~S}$ subunits, Met-tRNA ${ }_{i}{ }^{\text {Met }}$, and various combinations of eIFs (as indicated in the figures) in buffer A (20 mM Tris at $\mathrm{pH} 7.5,100 \mathrm{mM} \mathrm{KCl}$, $1 \mathrm{mM} \mathrm{DTT}, 2.5 \mathrm{mM} \mathrm{MgCl} 2,0.25 \mathrm{mM}$ spermidine) supplemented with $1 \mathrm{mM}$ ATP and $0.4 \mathrm{mM}$ GTP in the presence or absence of IFIT1, $\mathrm{m}^{7} \mathrm{GTP}, \mathrm{m}^{7} \mathrm{GpppA}$, or $\mathrm{m}^{7} \mathrm{G}$ (as indicated in the figures). Formation of $48 \mathrm{~S} / 80 \mathrm{~S}$ complexes was assayed by primer extension using AMV reverse transcriptase and $\left[{ }^{32} \mathrm{P}\right]$-labeled primers. cDNA products were resolved in a $6 \%$ acrylamide sequencing gel and visualized by autoradiography.

\section{Helicase assay}

A 13-nt-long RNA oligonucleotide was ${ }^{32} \mathrm{P}$-labeled with T4 polynucleotide kinase and annealed with complementary 38-nt-long RNA oligonucleotide. RNA duplex was purified on Superdex 75 , incubated with eIF4F for $40 \mathrm{~min}$ at $37^{\circ} \mathrm{C}$ in buffer B $(20 \mathrm{mM}$ HEPES at $\mathrm{pH} 7.5,2 \mathrm{mM}$ DTT, $5 \mathrm{mM} \mathrm{MgCl}_{2}, 5 \%$ glycerol, 2 $\mathrm{mM}$ ATP) in the presence of $1 \mathrm{mM}$ GTP or $\mathrm{m}^{7} \mathrm{GTP}$, analyzed in a $12 \%$ nondenaturing gel, and quantified by a phosphorimager.

\section{In vitro translation}

Uncapped $\beta$-globin, luciferase, and EMCV IRES-containing mRNAs were translated using the Flexi RRL system (Promega Corp.). Twenty-microliter reaction mixtures containing $0.4 \mu \mathrm{g}$ of mRNA and $\left.{ }^{35} \mathrm{~S}\right] \mathrm{methionine}$ were incubated for $30 \mathrm{~min}$ at $32^{\circ}$ $\mathrm{C}$ in the presence or absence of $0.5 \mathrm{mM}$ GTP, $\mathrm{m}^{7} \mathrm{GTP}$, or $\mathrm{m}^{7} \mathrm{GpppG}$ (as indicated in the figures). In some experiments, RRL was additionally supplemented with $2 \mu \mathrm{M}$ eIF4E and preincubated for $8 \mathrm{~min}$ at $32^{\circ} \mathrm{C}$ before addition of mRNA. Translation products were resolved by SDS-PAGE followed by phosphorimaging.

\section{UV cross-linking}

$\left[{ }^{32} \mathrm{P}\right]$ cap-labeled mRNAs were incubated with $40 \mathrm{~S}$ subunits, Met-tRNA ${ }_{i}{ }^{M e t}$, and different combinations of eIFs (as indicated) in buffer A supplemented with $0.05 \mathrm{mg} / \mathrm{mL}$ BSA and various nucleotides (as indicated) for $10 \mathrm{~min}$ at $37^{\circ} \mathrm{C}$. Assembled complexes were UV-irradiated at $254 \mathrm{~nm}$ and treated with RNases $\mathrm{A}, \mathrm{V} 1$, and $\mathrm{T} 1$, and cross-linked proteins were analyzed by SDS-PAGE, visualized by autoradiography, and quantified by a phosphoimager.

\section{Acknowledgments}

We thank K. Borden and T. Miura for the eIF4E expression vector, W. Gong for the eIF3k expression vector, and P. Jalinot for the eIF31 expression vector. This work was supported by National Institutes of Health grant GM59660 to T.V.P.

\section{References}

Abaeva IS, Marintchev A, Pisareva VP, Hellen CU, Pestova TV. 2011. Bypassing of stems versus linear base-by-base inspection of mammalian mRNAs during ribosomal scanning. EMBO J 30: 115-129.

Abaeva IS, Pestova TV, Hellen CU. 2016. Attachment of ribosomal complexes and retrograde scanning during initiation on the Halastavi árva virus IRES. Nucleic Acids Res 44: 2362-2377.

Abbas YM, Pichlmair A, Górna MW, Superti-Furga G, Nagar B. 2013. Structural basis for viral 5'-PPP-RNA recognition by human IFIT proteins. Nature 494: 60-64.

Bergmann JE, Lodish HF. 1979. Translation of capped and uncapped vesicular stomatitis virus and reovirus mRNAs. Sensitivity to $\mathrm{m}^{7} \mathrm{GpppAm}$ and ionic conditions. I Biol Chem 254: 459-468.

Berthelot K, Muldoon M, Rajkowitsch L, Hughes J, McCarthy JE. 2004. Dynamics and processivity of $40 S$ ribosome scanning on mRNA in yeast. Mol Microbiol 51: 987-1001.

Canaani D, Revel M, Groner Y. 1976. Translational discrimination of 'capped' and 'non-capped' mRNAs: inhibition of a series of chemical analogs of $\mathrm{m}^{7} \mathrm{GpppX}$. FEBS Lett 64: 326-331.

De Gregorio E, Preiss T, Hentze MW. 1998. Translational activation of uncapped mRNAs by the central part of human eIF4G is $5^{\prime}$ end-dependent. RNA 4: 828-836.

des Georges A, Dhote V, Kuhn L, Hellen CU, Pestova TV, Frank J, Hashem Y. 2015. Structure of mammalian eIF3 in the context of the 43S preinitiation complex. Nature 525: 491-495.

Elfakess R, Sinvani H, Haimov O, Svitkin Y, Sonenberg N, Dikstein R. 2011. Unique translation initiation of mRNAs-containing TISU element. Nucleic Acids Res 39: 7598-7609.

Ellisdon AM, Stewart M. 2012. Structural biology of the PCI-protein fold. Bioarchitecture 2: 118-123.

Fletcher L, Corbin SD, Browning KS, Ravel JM. 1990. The absence of $\mathrm{m}^{7} \mathrm{G}$ cap on $\beta$-globin mRNA and alfalfa mosaic virus RNA 4 increases the amounts of initiation factor $4 \mathrm{~F}$ required for translation. J Biol Chem 265: 19582-19587.

García-García C, Frieda KL, Feoktistova K, Fraser CS, Block SM. 2015. Factor-dependent processivity in human eIF4A DEADbox helicase. Science 348: 1486-1488.

Gross JD, Moerke NJ, von der Haar T, Lugovskoy AA, Sachs AB, McCarthy JE, Wagner G. 2003. Ribosome loading onto the mRNA cap is driven by conformational coupling between eIF4G and eIF4E. Cell 115: 739-750.

Hashem Y, des Georges A, Dhote V, Langlois R, Liao HY, Grassucci RA, Hellen CU, Pestova TV, Frank J. 2013. Structure of the mammalian ribosomal $43 \mathrm{~S}$ preinitiation complex bound to the scanning factor DHX29. Cell 153: 1108-1119.

He H, von der Haar T, Singh CR, Ii M, Li B, Hinnebusch AG, McCarthy JE, Asano K. 2003. The yeast eukaryotic initiation factor 4G (eIF4G) HEAT domain interacts with eIF1 and eIF5 and is involved in stringent AUG selection. Mol Cell Biol 23: 5431-5445.

Hinton TM, Coldwell MJ, Carpenter GA, Morley SJ, Pain VM. 2007. Functional analysis of individual binding activities of the scaffold protein eIF4G. J Biol Chem 282: 1695-1708.

Hussain T, Llácer JL, Fernández IS, Munoz A, Martin-Marcos P, Savva CG, Lorsch JR, Hinnebusch AG, Ramakrishnan V. 2014. Structural changes enable start codon recognition by the eukaryotic translation initiation complex. Cell 159: 597-607.

Imataka H, Sonenberg N. 1997. Human eukaryotic translation initiation factor 4G (eIF4G) possesses two separate and independent binding sites for eIF4A. Mol Cell Biol 17: 6940-6947. 
Jackson RJ, Hellen CU, Pestova TV. 2010. The mechanism of eukaryotic translation initiation and principles of its regulation. Nat Rev Mol Cell Biol 11: 113-127.

Kaye NM, Emmett KJ, Merrick WC, Jankowsky E. 2009. Intrinsic RNA binding by the eukaryotic initiation factor $4 \mathrm{~F}$ depends on a minimal RNA length but not on the $\mathrm{m}^{7} \mathrm{G}$ cap. I Biol Chem 284: 17742-17750.

Kolupaeva VG, Unbehaun A, Lomakin IB, Hellen CU, Pestova TV. 2005. Binding of eukaryotic initiation factor 3 to ribosomal 40 S subunits and its role in ribosomal dissociation and antiassociation. RNA 11: 470-486.

Kumar P, Sweeney TR, Skabkin MA, Skabkina OV, Hellen CU, Pestova TV. 2014. Inhibition of translation by IFIT family members is determined by their ability to interact selectively with the $5^{\prime}$-terminal regions of cap0-, cap1- and 5'pppmRNAs. Nucleic Acids Res 42: 3228-3245.

Lee AS, Kranzusch PJ, Cate JH. 2015. eIF3 targets cell-proliferation messenger RNAs for translational activation or repression. Nature 522: 111-114.

LeFebvre AK, Korneeva NL, Trutschl M, Cvek U, Duzan RD, Bradley CA, Hershey JW, Rhoads RE. 2006. Translation initiation factor eIF4G-1 binds to eIF3 through the eIF3e subunit. J Biol Chem 281: 22917-22932.

Li L, Wang CC. 2004. Capped mRNA with a single nucleotide leader is optimally translated in a primitive eukaryote, Giardia lamblia. J Biol Chem 279: 14656-14664.

Lindqvist L, Imataka H, Pelletier J. 2008. Cap-dependent eukaryotic initiation factor-mRNA interactions probed by crosslinking. RNA 14: 960-969.

Llácer JL, Hussain T, Marler L, Aitken CE, Thakur A, Lorsch JR, Hinnebusch AG, Ramakrishnan V. 2015. Conformational differences between open and closed states of the eukaryotic translation initiation complex. Mol Cell 59: 399-412.

Lomakin IB, Hellen CU, Pestova TV. 2000. Physical association of eukaryotic initiation factor 4G (eIF4G) with eIF4A strongly enhances binding of eIF4G to the internal ribosomal entry site of encephalomyocarditis virus and is required for internal initiation of translation. Mol Cell Biol 20: 60196029.

Maag D, Fekete CA, Gryczynski Z, Lorsch JR. 2005. A conformational change in the eukaryotic translation preinitiation complex and release of eIF1 signal recognition of the start codon. Mol Cell 17: 265-275.

Mader S, Lee H, Pause A, Sonenberg N. 1995. The translation initiation factor eIF-4E binds to a common motif shared by the translation factor eIF- $4 \gamma$ and the translational repressors 4Ebinding proteins. Mol Cell Biol 15: 4990-4997.

Marintchev A, Edmonds KA, Marintcheva B, Hendrickson E, Oberer M, Suzuki C, Herdy B, Sonenberg N, Wagner G. 2009. Topology and regulation of the human eIF4A/4G/4H helicase complex in translation initiation. Cell 136: 447460.

Masutani M, Sonenberg N, Yokoyama S, Imataka H. 2007. Reconstitution reveals the functional core of mammalian eIF3. EMBO I 26: 3373-3383.

Mazza C, Segref A, Mattaj IW, Cusack S. 2002. Large-scale induced fit recognition of an $\mathrm{m}^{7} \mathrm{GpppG}$ cap analogue by the human nuclear cap-binding complex. EMBO J 21: 5548-5557.

Morais AT, Meza AN, Araújo GC, Vidotto A, Souza FP, Fossey MA, Murakami MT, Nogueira ML. 2014. Biophysical and structural characterization of the recombinant human eIF3L. Protein Pept Lett 21: 56-62.

Morino S, Imataka H, Svitkin YV, Pestova TV, Sonenberg N. 2000. Eukaryotic translation initiation factor 4E (eIF4E) binding site and the middle one-third of eIF4GI constitute the core domain for cap-dependent translation, and the C-terminal one-third functions as a modulatory region. Mol Cell Biol 20: 468-477.

Morris C, Wittmann J, Jäck HM, Jalinot P. 2007. Human INT6/ eIF3e is required for nonsense-mediated mRNA decay. ЕМBO Rep 8: 596-602.

Niedzwiecka A, Marcotrigiano J, Stepinski J, Jankowska-Anyszka M, Wyslouch-Cieszynska A, Dadlez M, Gingras AC, Mak P, Darzynkiewicz E, Sonenberg N, et al. 2002. Biophysical studies of eIF4E cap-binding protein: recognition of mRNA $5^{\prime}$ cap structure and synthetic fragments of eIF4G and 4E-BP1 proteins. J Mol Biol 319: 615-635.

Ohlmann T, Rau M, Pain VM, Morley SJ. 1996. The C-terminal domain of eukaryotic protein synthesis initiation factor (eIF) 4G is sufficient to support cap-independent translation in the absence of eIF4E. EMBO J 15: 1371-1382.

Pestova TV, Kolupaeva VG. 2002. The roles of individual eukaryotic translation initiation factors in ribosomal scanning and initiation codon selection. Genes Dev 16: 2906-2922.

Pestova TV, de Breyne S, Pisarev AV, Abaeva IS, Hellen CU. 2008. eIF2-dependent and eIF2-independent modes of initiation on the CSFV IRES: a common role of domain II. EMBO I 27: 1060-1072.

Pisarev AV, Kolupaeva VG, Pisareva VP, Merrick WC, Hellen CU, Pestova TV. 2006. Specific functional interactions of nucleotides at key -3 and +4 positions flanking the initiation codon with components of the mammalian $48 \mathrm{~S}$ translation initiation complex. Genes Dev 20: 624-636.

Pisarev AV, Kolupaeva VG, Yusupov MM, Hellen CU, Pestova TV. 2008. Ribosomal position and contacts of mRNA in eukaryotic translation initiation complexes. EMBO I 27: $1609-1621$.

Pisareva VP, Pisarev AV, Komar AA, Hellen CU, Pestova TV. 2008. Translation initiation on mammalian mRNAs with structured 5'UTRs requires DExH-box protein DHX29. Cell 135: 1237-1250.

Quiocho FA, Hu G, Gershon PD. 2000. Structural basis of mRNA cap recognition by proteins. Curr Opin Struct Biol 10: 78-86.

Schoggins JW, Wilson SJ, Panis M, Murphy MY, Jones CT, Bieniasz P, Rice CM. 2011. A diverse range of gene products are effectors of the type I interferon antiviral response. Nature 472: 481-485.

Siridechadilok B, Fraser CS, Hall RJ, Doudna JA, Nogales E. 2005. Structural roles for human translation factor eIF3 in initiation of protein synthesis. Science 310: 1513-1515.

Skabkin MA, Skabkina OV, Hellen CU, Pestova TV. 2013. Reinitiation and other unconventional posttermination events during eukaryotic translation. Mol Cell 51: 249-264.

Slepenkov SV, Korneeva NL, Rhoads RE. 2008. Kinetic mechanism for assembly of the $\mathrm{m}^{7} \mathrm{GpppG}$.eIF4E.eIF4G complex. J Biol Chem 283: 25227-25237.

Sonenberg N, Shatkin AJ. 1977. Reovirus mRNA can be covalently crosslinked via the $5^{\prime}$ cap to proteins in initiation complexes. Proc Natl Acad Sci 74: 4288-4292.

Sonenberg N, Shatkin AJ. 1978. Nonspecific effect of $\mathrm{m}^{7} \mathrm{GMP}$ on protein-RNA interactions. J Biol Chem 253: 6630-6632.

Sonenberg N, Morgan MA, Testa D, Colonno RJ, Shatkin AJ. 1979a. Interaction of a limited set of proteins with different mRNAs and protection of 5 -caps against pyrophosphatase digestion in initiation complexes. Nucleic Acids Res 7: 15-29.

Sonenberg N, Rupprecht KM, Hecht SM, Shatkin AJ. 1979b. Eukaryotic mRNA cap binding protein: purification by affinity 
chromatography on sepharose-coupled $\mathrm{m}^{7} \mathrm{GDP}$. Proc Natl Acad Sci 76: 4345-4349.

Tcherkezian J, Cargnello M, Romeo Y, Huttlin EL, Lavoie G, Gygi SP, Roux PP. 2014. Proteomic analysis of cap-dependent translation identifies LARP1 as a key regulator of 5'TOP mRNA translation. Genes Dev 28: 357-371.

Thoreen CC, Chantranupong L, Keys HR, Wang T, Gray NS, Sabatini DM. 2012. A unifying model for mTORC1-mediated regulation of mRNA translation. Nature 485: 109-113.

Tomoo K, Shen X, Okabe K, Nozoe Y, Fukuhara S, Morino S, Ishida T, Taniguchi T, Hasegawa H, Terashima A, et al. 2002. Crystal structures of 7-methylguanosine $5^{\prime}$-triphosphate $\left(\mathrm{m}^{7} \mathrm{GTP}\right)$ - and $\mathrm{P}^{1}$-7-methylguanosine- $\mathrm{P}^{3}$-adenosine-5', $5^{\prime}$-triphosphate $\left(\mathrm{m}^{7} \mathrm{GpppA}\right)$-bound human full-length eukaryotic initiation factor 4E: biological importance of the C-terminal flexible region. Biochem J 362: 539-544.

Villa N, Do A, Hershey JW, Fraser CS. 2013. Human eukaryotic initiation factor $4 \mathrm{G}$ (eIF4G) protein binds to eIF3c, -d, and -e to promote mRNA recruitment to the ribosome. I Biol Chem 288: 32932-32940. von der Haar T, Gross JD, Wagner G, McCarthy JE. 2004. The mRNA cap-binding protein eIF4E in post-transcriptional gene expression. Nat Struct Mol Biol 11: 503-511.

Yanagiya A, Svitkin YV, Shibata S, Mikami S, Imataka H, Sonenberg N. 2009. Requirement of RNA binding of mammalian eukaryotic translation initiation factor 4GI (eIF4GI) for efficient interaction of eIF4E with the mRNA cap. Mol Cell Biol 29: 1661-1669.

Yu Y, Abaeva IS, Marintchev A, Pestova TV, Hellen CU. 2011. Common conformational changes induced in type 2 picornavirus IRESs by cognate trans-acting factors. Nucleic Acids Res 39: 4851-4865.

Zhou M, Sandercock AM, Fraser CS, Ridlova G, Stephens E, Schenauer MR, Yokoi-Fong T, Barsky D, Leary JA, Hershey JW, et al. 2008. Mass spectrometry reveals modularity and a complete subunit interaction map of the eukaryotic translation factor eIF3. Proc Natl Acad Sci 105: 18139-18144.

Zinoviev A, Hellen CU, Pestova TV. 2015. Multiple mechanisms of reinitiation on bicistronic calicivirus mRNAs. Mol Cell 57: 1059-1073. 


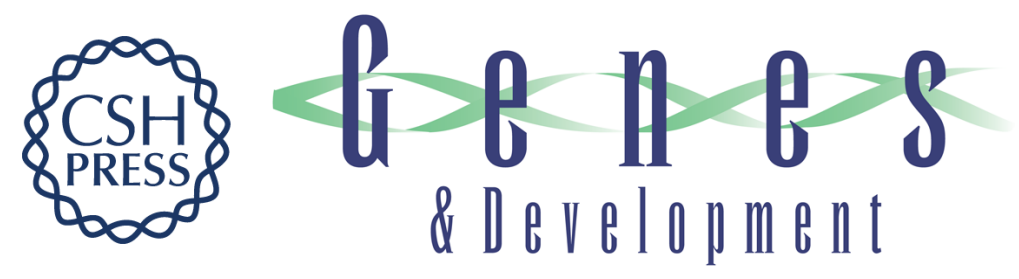

\section{Toward the mechanism of elF4F-mediated ribosomal attachment to mammalian capped mRNAs}

Parimal Kumar, Christopher U.T. Hellen and Tatyana V. Pestova

Genes Dev. 2016, 30:

Access the most recent version at doi:10.1101/gad.282418.116

Supplemental
Material http://genesdev.cshlp.org/content/suppl/2016/07/11/30.13.1573.DC1

References This article cites 61 articles, 33 of which can be accessed free at:

http://genesdev.cshlp.org/content/30/13/1573.full.html\#ref-list-1

Creative This article is distributed exclusively by Cold Spring Harbor Laboratory Press for the first Commons

License

Email Alerting

Service six months after the full-issue publication date (see

http://genesdev.cshlp.org/site/misc/terms.xhtml). After six months, it is available under a Creative Commons License (Attribution-NonCommercial 4.0 International), as described at http://creativecommons.org/licenses/by-nc/4.0/.

Receive free email alerts when new articles cite this article - sign up in the box at the top right corner of the article or click here.

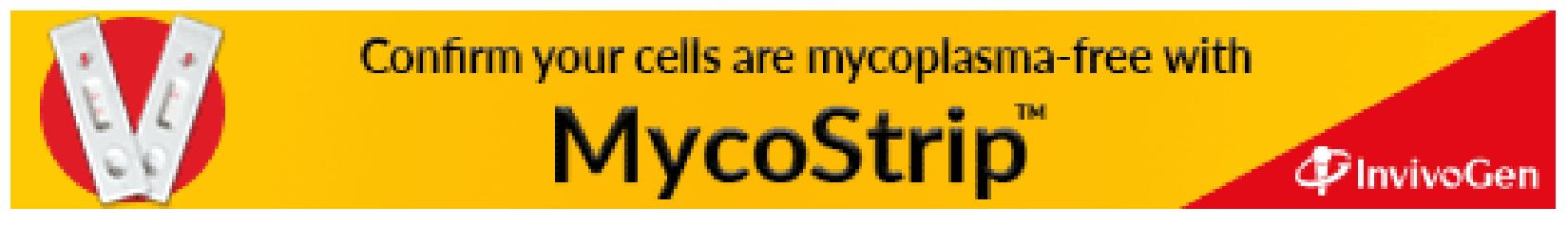

